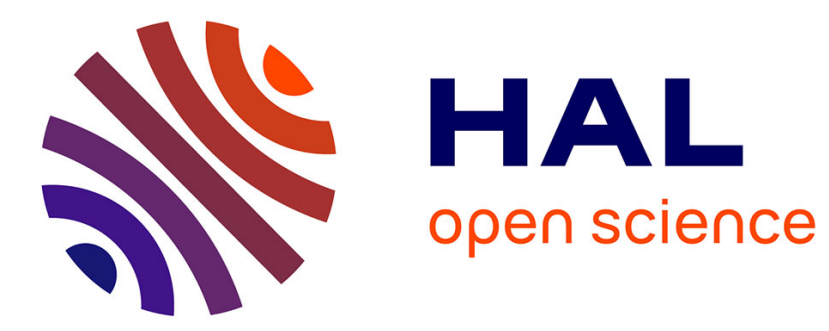

\title{
Impact of carbonation on unsaturated water transport properties of cement-based materials
}

Martin Auroy, Stéphane Poyet, Patrick Le Bescop, Jean-Michel Torrenti, Thibault Charpentier, Mélanie Moskura, Xavier Bourbon

\section{To cite this version:}

Martin Auroy, Stéphane Poyet, Patrick Le Bescop, Jean-Michel Torrenti, Thibault Charpentier, et al.. Impact of carbonation on unsaturated water transport properties of cement-based materials. Cement and Concrete Research, 2015, 74, pp.44-58. 10.1016/j.cemconres.2015.04.002 . cea-01272793

\section{HAL Id: cea-01272793 \\ https://hal-cea.archives-ouvertes.fr/cea-01272793}

Submitted on 11 Feb 2016

HAL is a multi-disciplinary open access archive for the deposit and dissemination of scientific research documents, whether they are published or not. The documents may come from teaching and research institutions in France or abroad, or from public or private research centers.
L'archive ouverte pluridisciplinaire HAL, est destinée au dépôt et à la diffusion de documents scientifiques de niveau recherche, publiés ou non, émanant des établissements d'enseignement et de recherche français ou étrangers, des laboratoires publics ou privés. 


\section{Impact of carbonation on unsaturated water}

\section{2 transport properties of cement-based materials}

3 Martin AUROY ${ }^{a}$, Stéphane POYET ${ }^{a}$, Patrick LE BESCOP ${ }^{a}$, Jean-Michel TORRENTI ,

4 Thibault CHARPENTIER ${ }^{c}$, Mélanie MOSKURA ${ }^{\mathrm{c}}$, Xavier BOURBON $^{d}$

$5 \quad$ a CEA, DEN, DPC, SECR, Laboratoire d'Etude du Comportement des Bétons et des Argiles, F-91191

6 Gif-sur-Yvette, France.

7 b Université Paris-Est, IFSTTAR, Département Matériaux \& Structures, 14-52 Boulevard Newton,

8 F-77447 Marne la Vallée Cedex 2, France.

9

${ }^{\circ}$ CEA, DSM, IRAMIS, NIMBE, Laboratoire Structure et Dynamique par Résonance Magnétique, CEA/CNRS UMR 3299, F-91191 Gif-sur-Yvette, France.

${ }^{d}$ Andra, Parc de la Croix Blanche, 1-7 rue Jean Monnet, 92298 Chatenay-Malabry Cedex, France.

Corresponding author: Stéphane Poyet

CEA Saclay, DEN/DPC/SECR/Laboratoire d'Etude du Comportement des Bétons et des Argiles, Bâtiment 158, Point Courrier 25, F-91191 Gif sur Yvette cedex, France.

Phone: +33 1690850 59; Fax: +33 1690884 41; E-mail : stephane.poyet@cea.fr

\section{Abstract}

In unsaturated conditions, the durability of concrete structures is strongly dependent on the evolution of the amount of free water within concrete porosity. Reliable durability assessment of concrete structures in relation to their environment thus requires accurate unsaturated water transport description as well as reliable input data. The effect of carbonation on water transport remains poorly studied and data are lacking. It was then the purpose of this article to acquire all the data needed to describe unsaturated water transport in carbonated cementitious materials (porosity, water retention and unsaturated permeability). Four hardened pastes made with four different binders were carbonated at $3 \% \mathrm{CO}_{2}$ to ensure representativeness with natural carbonation. Beyond the modification 
of the water retention curve and porosity clogging, significant microcracking due to carbonation shrinkage was observed. The consequence on permeability highlighted a competition between porosity clogging and microcracking that was dependent on the initial mineralogical composition.

Keywords: waste management (E); cement paste (D); drying (A); permeability (C); microstructure (B)

\section{Introduction}

In unsaturated conditions, the durability of concrete structures is strongly dependent on the evolution of the amount of free water within concrete porosity (the term "free water" means the water that can be evaporated: it includes capillary and adsorbed water). This dependence is well illustrated by the results of Tuutti [1] that show the strong evolution of the corrosion current (over several orders of magnitude) of steel embedded in a carbonated mortar as a function of the external relative humidity $(\mathrm{RH})$. In a more general way water significantly influences concrete performances and durability (shrinkage, creep, cracking, transport properties). Reliable durability assessment of concrete structures in relation to their environment thus requires accurate unsaturated water transport description. Many studies were published on this specific subject and a lot of data were acquired in the laboratory using different cement-based materials taking care to avoid interaction with carbon dioxide $\left(\mathrm{CO}_{2}\right)$. These results are of course very important but they are not fully relevant for durability appraisal because they disregard the fact that concrete structures are being carbonated when exchanging water with the environment.

Carbonation refers to the reaction between the calcium contained in concrete pore solution and gaseous $\mathrm{CO}_{2}$. It leads to hydrates dissolution (mainly portlandite and $\mathrm{C}-\mathrm{S}-\mathrm{H}$ ) and precipitation of calcium carbonate $\left(\mathrm{CaCO}_{3}\right)$. Beyond the fall of the pore solution $\mathrm{pH}$ that triggers rebar depassivation and corrosion, the precipitation of $\mathrm{CaCO}_{3}$ generates porosity clogging: the reduction of which depends on the cement type and water to cement ratio $(w / c)[2-8]$. The specific surface area is then significantly decreased (around 50\%) despite conflicting observations $[9,10]$.

The pore size distribution is also altered. Litvan and Meyer [11] studied carbonated concrete samples taken from a 20-year field exposure test (two concretes made with CEM I and CEM III). They found that carbonation led to significant coarsening of the pore structure of the CEM III concrete whereas the finer pores were affected for the CEM I one. Using pastes with different w/c (from 0.4 to 0.7 ) Ngala 


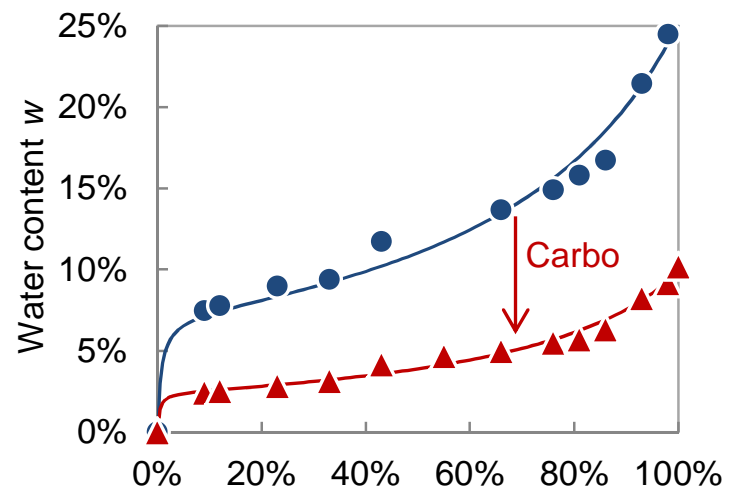

$\mathrm{RH}$ was obtained for pastes containing fly ash. mortars $(\mathrm{w} / \mathrm{c}=0.5)$ after carbonation $\left(50 \% \mathrm{CO}_{2}\right)$ (Figure 2).

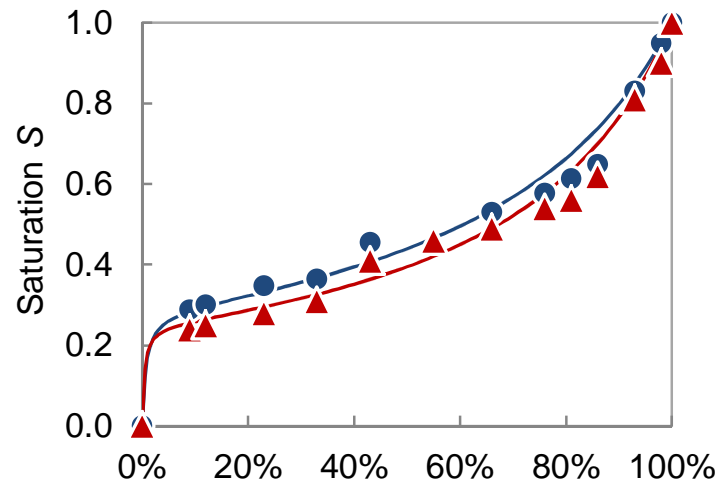

$\mathrm{RH}$

and Page [5] found that carbonation (using $5 \%$ of $\mathrm{CO}_{2}$ ) increased the proportion of capillary pores (pores larger than $30 \mathrm{~nm}$ ) whatever the binder and water to binder ratio. More recently, Thiéry et al. [7] carbonated CEM I pastes with different w/c (using $50 \%$ of $\mathrm{CO}_{2}$ ) and found that carbonation was capable of producing large capillary pores (larger than $100 \mathrm{~nm}$ ) for w/c greater than 0.45 . This could be just a consequence of the high $\mathrm{CO}_{2}$ content used in this study because the authors noted that this phenomenon was reproduced using $10 \%$ of $\mathrm{CO}_{2}$. Morandeau $[12,13]$ conducted similar experiments using CEM I pastes with or without fly ash (using $10 \%$ of $\mathrm{CO}_{2}$ ). The pore volume of the CEM I pastes was almost uniformly reduced over the whole pore size distribution whereas a significant coarsening

The water retention curves (i.e. adsorption and desorption isotherms) are also transformed. Due to porosity clogging, the water retained at equilibrium is significantly reduced [2, 4, 14-16]. In addition, using CEM I pastes of different w/c Houst [14], Houst and Wittmann [4] $\left(\approx 90 \% \mathrm{CO}_{2}\right)$ and Thiéry et al. [7] $\left(50 \% \mathrm{CO}_{2}\right)$ showed that despite this reduction in water content (in percent by dry mass) the curves remained unchanged when they were expressed in saturation (Figure 1). This highlights the change in density induced by carbonation due to $\mathrm{CO}_{2}$ fixation $\left(1.60\right.$ and $2.03 \mathrm{~g} / \mathrm{cm}^{3}$ for non- and carbonated pastes respectively as estimated using mercury intrusion porosimetry [14]). This also means that all the pores were impacted in the same manner by $\mathrm{CaCO}_{3}$ precipitation. This is of course not consistent with the coarsening of the pore structure discussed above. This is also not consistent with the results of Hyvert [16] who obtained significant alteration of the water retention curve of CEM I and CEM III/A

Figure 1: Effect of carbonation on the desorption isotherm of a CEM I paste $(w / c=0.4)$, redrawn after [14]. Key: $\bullet$ non-carbonated paste, $\Delta$ carbonated paste. 

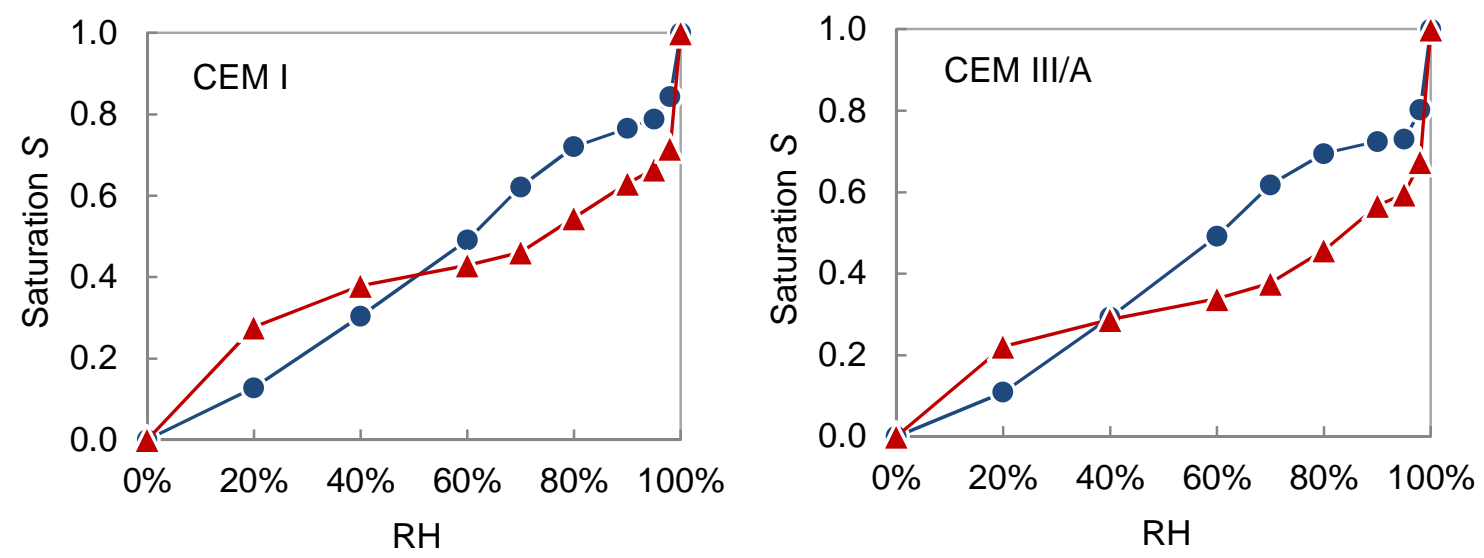

Figure 2: Effect of carbonation on the desorption isotherm of CEM I and CEM III/A mortars $(w / c=0.5)$, redrawn after [16]. Key: $\bullet$ non-carbonated paste, $\Delta$ carbonated paste.

The effect of carbonation on permeability is also controversial. Martin [17] used $\mathrm{CO}_{2}$ in gas permeability tests and observed a reduction in permeability as a consequence of carbonation during the test. Using CEM I grouts, Dewaele et al. [9] obtained permeability decrease of several orders of magnitude after carbonation (by injection under pressure of $\mathrm{CO}_{2}$-rich water). Claisse et al. [6] carbonated CEM I concretes $\left(5 \% \mathrm{CO}_{2}\right)$ and measured significant increase in the so-called impermeability index [18] indicating a fall in permeability. In the same way Song and Kwon [19] carbonated two CEM I concretes and found that the permeability coefficient of the carbonated concretes was three times less than that of the non-carbonated ones. These results are however not consistent with the observations of Borges et al. [20] who measured oxygen permeability on CEM I paste with or without slag (75\% and $90 \%)$. The CEM I paste permeability values remained stable after carbonation $\left(5 \% \mathrm{CO}_{2}\right)$ whereas the pastes incorporating slag showed significant increase in permeability. Moreover Thiéry et al. [7] and Wang et al. [21] showed that for a high w/c CEM I concrete (0.84) the permeability (evaluated using inverse analysis) was increased after carbonation (by one order of magnitude).

In summary, there are not enough studies dealing with the effect of carbonation on water transport properties and the results are piecemeal and often conflicting. This might be due to differences in $\mathrm{CO}_{2}$ content, cement type or even mix composition. It is then the purpose of this article to study the effect of carbonation and to acquire all the data needed to describe unsaturated water transport in carbonated cement pastes; that is to say: porosity, water retention curve and unsaturated permeability (see section 2). 


\section{Theoretical framework}

98

99

100

101

102

103

104

105

106

107

108

109

110

111

112

Water transport within concretes involves three mechanisms: (I) permeation of the liquid phase; (ii) permeation of the gaseous phase (mix of vapour and dry air) and (iii) diffusion of vapour within the gaseous phase (the transport of adsorbed water is not accounted for here). The description of these phenomena results in a complex set of coupled differential equations [22-25]. The major disadvantage of this approach is the great number of input data that are required and the experimental difficulty related to their assessment.

Water transport is then usually described in a simplified way using a single equation as for liquid permeation only (the two other motions are included). This approach was found to be valid (water transport in the gaseous phase was found to be negligible compared liquid permeation) for weakly permeable materials [24]: this was the case for a concrete with an intrinsic permeability equal to $1 \times 10^{-}$ ${ }^{21} \mathrm{~m}^{2}$ [26]. More recently, Thiéry et al. [27, 28] estimated the respective contribution of each motion for three different concretes. They showed that this approach validity depends on the intrinsic permeability and the RH-domain that is considered. For instance for a high-performance concrete with low permeability $\left(\approx 2 \times 10^{-22} \mathrm{~m}^{2}\right)$ the assumption appears to be valid between $\mathrm{RH}=20 \%$ and $100 \%$ whereas for a low-strength concrete with high permeability $\left(\approx 4 \times 10^{-19} \mathrm{~m}^{2}\right)$ the validity domain is limited to $65 \%$ $100 \% \mathrm{RH}$.

To describe water transport in a simplified way, we have started using Darcy's law extended to unsaturated flow [29] which allowed estimating the water flux $j$ :

$$
\underline{j}=-\rho \frac{K_{e}}{\eta} \underline{\operatorname{grad}}(P)
$$

where $P$ is the liquid pressure $[\mathrm{Pa}] ; \eta$ and $\rho$ the water viscosity $[\mathrm{Pa} \cdot \mathrm{s}]$ and density $\left[\mathrm{kg} / \mathrm{m}^{3}\right]$ respectively. $K_{e}$ is the effective permeability that characterizes the resistance of the unsaturated concrete to water flow (under a pressure gradient) $\left[\mathrm{m}^{2}\right]$. It was expressed as the product $\left(K \times k_{r}\right)$ in which $K$ is the intrinsic permeability [m²] and $k_{r}$ the relative permeability that accounts for the effect of desaturation on the depercolation of the saturated porous network (ranges between 0 and 1). The mass conservation equation then wrote:

$$
\frac{\partial}{\partial t}(\rho \emptyset S)=-\operatorname{div}(\underline{j})=\operatorname{div}\left[\rho \frac{K_{e}}{\eta} \underline{\operatorname{grad}}(P)\right]
$$


$S$ is the saturation index [without unit], it describes how pores are filled with liquid water and ranges between 0 (dry state) and 1 (saturated state). $\emptyset$ is the concrete porosity (volume per volume) [without unit]. In isothermal conditions, assuming that water is incompressible and that a differentiable relation between saturation $S$ and water pressure $P$ exists (this relation is known as the capillary pressure curve) eq. (3) could be easily obtained:

$$
\emptyset\left(\frac{\partial S}{\partial P}\right) \frac{\partial P}{\partial t}=\operatorname{div}\left[\frac{K_{e}}{\eta} \underline{\operatorname{grad}}(P)\right]-S\left(\frac{\partial \emptyset}{\partial t}\right)
$$

The right-hand term $\left(S \frac{\partial \emptyset}{\partial t}\right)$ accounted for porosity reduction induced by carbonation and the pressure $P$ was calculated using the so-called Kelvin-Laplace equation:

$$
P(h)=-\rho \frac{R T}{M} \ln (h)
$$

$R$ is the universal gas constant $[\mathrm{J} / \mathrm{mol} / \mathrm{K}], T$ is the absolute temperature $[\mathrm{K}] . M$ is the liquid water molar mass $[\mathrm{kg} / \mathrm{mol}]$ and $h$ is the relative humidity. The description of water transport within concrete thus required the knowledge of only three physical parameters: the concrete porosity $(\varnothing)$, the effective permeability $\left(K_{e}\right)$ and the left-hand term $\left(\frac{\partial S}{\partial P}\right)$ which was assessed using the water retention curve [30]. It must be noted that for constant porosity, eq. (3) could be simplified to eq. (5) which was used to describe unsaturated water transport in the non-carbonates pastes (part 4.4.1).

$$
\emptyset\left(\frac{\partial S}{\partial P}\right) \frac{\partial P}{\partial t}=\operatorname{div}\left[\frac{K_{e}}{\eta} \underline{\operatorname{grad}}(P)\right]
$$

\section{Materials and specimens}

\subsection{Materials}

Four different hardened cement pastes with constant water to binder ratio $(0.40)$ were used (Table 1$)$. These binders were chosen because they are being used for R\&D studies by the French Agency for radioactive waste management (Andra) and its partners. The low-pH mix was designed in the field of geological disposal to limit the chemical interaction between clay minerals and concrete structures [31, 32]. The CEM I, CEM V/A and Low-pH mix were already studied in a previous work $[33,34]$ in which the water transport properties of the non-carbonated materials were characterized. The cement pastes CEM I, CEM III/A, CEM V/A and Low-pH blend (T1 from [32]) are respectively noted PI, PIII, PV and PBP in this study. 
Table 1: Cement pastes composition.

\begin{tabular}{ccccc}
\hline Compound & CEM I & CEM III/A & CEM V/A & Low-pH blend (T1) \\
\hline CEM I & $100 \%$ & $39 \%$ & $56 \%$ & $37.5 \%$ \\
Slag & - & $61 \%$ & $22 \%$ & - \\
Fly ash & - & - & $22 \%$ & $30 \%$ \\
Silica fume & - & - & - & $32.5 \%$ \\
Superplasticizer Chryso ${ }^{(\otimes}$ Fluid Optima 175 & - & - & - & $1 \%$ of binder (by mass) \\
Water to binder ratio & 0.40 & 0.40 & 0.40 & 0.40 \\
\hline
\end{tabular}

\subsection{Specimens preparation}

The pastes were prepared in twelve consecutive batches of $2 L$ ( 3 batches for each composition) over two days. The appropriate amounts of cement and water were mixed in a planetary mixer until homogenization of the fresh mix. The paste was then poured into polypropylene cylindrical moulds $(\varnothing 50 \times 100 \mathrm{~mm})$ and vibrated to remove entrapped air bubbles. The specimens were kept two weeks after casting in their sealed moulds before unmoulding. The specimens were then cured for four months in sealed containers immersed in specific curing solutions. The composition of the curing solutions of the PI, PIII and PV specimens was designed to prevent calcium and alkalis leaching. The pore solutions were expressed at high-pressure [35] from specimens kept in sealed moulds for 4 months. The use of the device optimized by Cyr \& Daidié [36] allowed retrieving several millilitres of solution, the composition of which was analyzed using ionic chromatography (Table 2).

Because the pore-solution of PBP was known to exhibit significant changes during the early months of hydration [32], a different protocol was chosen: several specimens were reduced into a rough powder and added to deionized water to generate the curing solution.

Table 2: lon chromatography results for the pore solutions of PI, PIII and PV.

\begin{tabular}{cccc}
\hline Cations $(\mathrm{mmol} / \mathrm{L})$ & $\mathrm{PI}$ & $\mathrm{PIII}$ & $\mathrm{PV}$ \\
\hline $\mathrm{Na}^{+}$ & 52 & 130 & 98 \\
$\mathrm{~K}^{+}$ & 473 & 366 & 469 \\
$\mathrm{Ca}^{2+}$ & 2.5 & 2.3 & 2.0 \\
\hline $\mathrm{pH}$ & 13.6 & 13.5 & 13.5 \\
\hline
\end{tabular}

164 The top and bottom parts of the samples that present different properties from the bulk [37-39] were cut off and discarded. The thickness of the parts to be removed was assessed by using accelerated 
chemical degradation [40]. One specimen of each paste was immersed in ammonium nitrate solution (6 mol/L). The leaching solution was stirred constantly but not renewed [41]. After one month, the samples were withdrawn from the solution, sawn in two parts and sprayed with phenolphthalein solution. Three zones could be observed (Figure 3):

- the central part where the degradation depth was constant versus height,

- the bottom part where the degradation depth was less due to sedimentation,

- the top part where the degradation depth was higher due to bleeding and sedimentation.

The removal of top and bottom ends $(10 \mathrm{~mm}$ ) was believed to yield homogeneous properties versus height. 140 disks per paste (6 mm-thick) were sawn from the central part of the resulting specimens. Most of these disks (110 per paste) were used for carbonation study and the remaining part was dedicated to the non-carbonated pastes characterization.
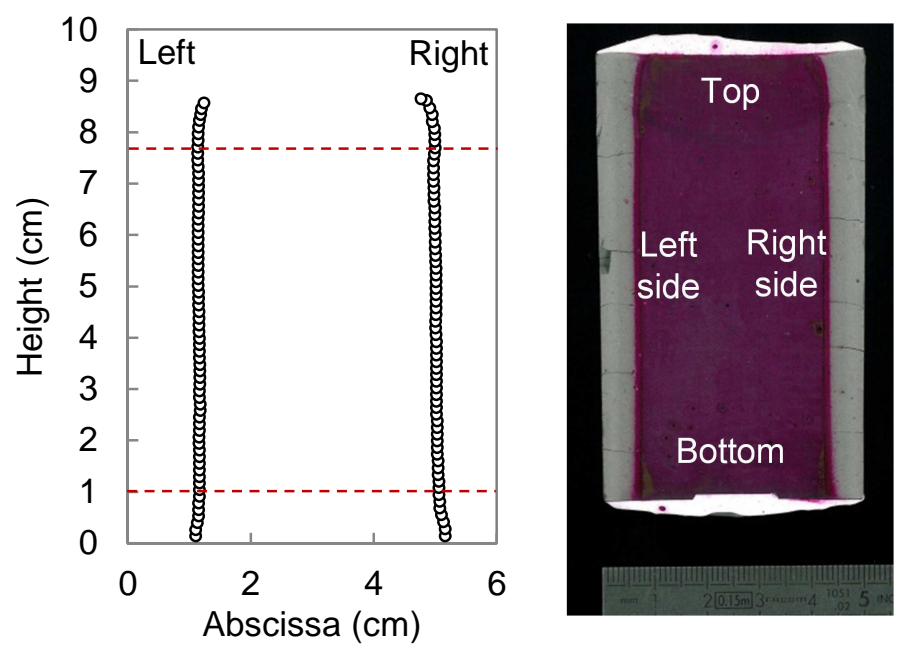

Figure 3: Degradation profile of PI sample after one month in ammonium nitrate (6M) at ambient temperature.

\subsection{Accelerated carbonation}

Accelerated carbonation was achieved using the device developed by Drouet [33]. It includes a climatic chamber for environmental control and a specific system allowing an accurate regulation of the $\mathrm{CO}_{2}$ partial pressure. Prior to carbonation, the 440 disks were kept in the carbonation device without $\mathrm{CO}_{2}\left(25^{\circ} \pm 0.2^{\circ} \mathrm{C}\right.$ and $\left.55 \pm 1 \% \mathrm{RH}\right)$ in order to reach a constant value of saturation that promotes carbonation [3, 42-44]. One month later, the equilibrium was reached (constant mass variation) and the carbonation test was started with a $\mathrm{CO}_{2}$ content of $3.0 \pm 0.2 \%$. This value was 
chosen to ensure representativeness of the mineralogical evolution compared to atmospheric carbonation [45]. The carbonation progress was monitored in a simple way through mass variation. The process was pursued until the complete carbonation state which was verified afterwards using Xray diffraction (XRD) and thermogravimetric analysis (TGA) (see section 5.1.).

\section{Methods}

\subsection{Mineralogical assemblage}

The mineralogical changes induced by carbonation were identified using a PANalytical X'Pert diffractometer and Cu Ka radiation $(\lambda=1,54 \AA)(X R D)$. The solid samples surface was scanned between 5 and $65^{\circ}$, with a step size of $0.017^{\circ}$. The use of the $X^{\prime}$ Celerator detector allowed the acquisition time of the diffractograms to be around 20 minutes.

Thermogravimetric analysis experiments (TGA) were accomplished using a NETZSCH STA 409 PC LUXX device to determine the amount of portlandite $(\mathrm{CH})$ and calcium carbonate $(\mathrm{C} \overline{\mathrm{C}})$. Following current methodology [46] the samples were powdered $(120 \pm 0.1 \mathrm{mg})$ and tested at a constant heating rate of $10^{\circ} \mathrm{C} / \mathrm{min}$ up to $1150^{\circ} \mathrm{C}$ under $\mathrm{N}_{2}$ flowrate $(80 \mathrm{~mL} / \mathrm{min})$.

The C-S-H content was evaluated following the method proposed by Olson and Jennings [47] and the water content at equilibrium with $\mathrm{RH}=20 \%$ (input data for the estimation process) was obtained from the water desorption isotherms.

${ }^{29}$ Si Magic Angle Spinning (MAS) Nuclear Magnetic Resonance (NMR) was used to probe the effect of carbonation on the C-S-H structure as commonly done [45, 48-51]. We did not use ${ }^{13} \mathrm{C}$ NMR because it was found difficult to distinguish one calcium carbonate from the others [52]. The ${ }^{29} \mathrm{Si}$ MAS NMR experiments were conducted following the current protocol of Brunet et al. [53]. Spectra were collected using a Bruker 300WB NMR spectrometer operating at a Larmor frequency of $59.3 \mathrm{MHz}$ (magnetic field 7.05 T). Samples intended for MAS NMR analysis were powdered (around $100 \mathrm{mg}$ sieved to remove the particles larger than $100 \mu \mathrm{m}$ ) and packed in $\mathrm{ZrO}_{2} 4 \mathrm{~mm}$ (outer diameter) rotors. Sample spinning frequency was $10,000 \mathrm{~Hz}$ and recycle delay was 2 s. No differences in line shape were seen for longer recycle delays (20s, 200s) and spin rate of $10 \mathrm{kHz}$ was found to be sufficient to remove 
paramagnetic effects (i.e. here spinning sidebands intensity minimized). Data were processed using an in-house made software [53].

214

\subsection{Porosity}

Water porosity $\emptyset$ was obtained using oven-drying. The specimens were preliminarily saturated under vacuum and water following the current standard used in France [54]. $80^{\circ} \mathrm{C}$ was chosen as the reference temperature in order to enable comparison with a previous study focused on similar materials [33] but supplementary tests were conducted at $105^{\circ} \mathrm{C}$ to enable comparison with literature.

The pore size distribution was investigated by mercury intrusion porosimetry (MIP) using a Micrometrics Autopore IV. Samples were crushed into small parts (several millimetres), frozen by immersion into liquid nitrogen, let to dry under vacuum for seven days and then tested at $20 \pm 2^{\circ} \mathrm{C}$. Two samples of each formulation were used.

\subsection{Water desorption isotherm}

The desorption isotherms were characterized using the desiccator method [55]. The non-carbonated samples were tested just after the cure (after 4 months) whereas the carbonated ones were tested after the cure ( 4 months) and carbonation ( 1 year). All the samples were resaturated before the test ( $4 \mathrm{~h}$ under vacuum and then $20 \mathrm{~h}$ under water and vacuum). A set of specimens (from 3 to 6 ) of each paste was inserted into a desiccator above a specific saturated salt solution to control the $\mathrm{RH}$ (Table 3). Thirteen different sample-sets were placed simultaneously into thirteen different desiccators including different salt solutions. This procedure allowed reducing the test duration, but might have resulted in increasing variability.

Table 3 Saturated salt solutions used in the desiccator method [56-59].

\begin{tabular}{ccc}
\hline Saturated salt solution & Chemical formula & $\mathrm{RH}\left(20^{\circ} \mathrm{C}\right)$ \\
\hline Calcium chloride & $\mathrm{CaCl}_{2}$ & $\approx 3 \%$ \\
Lithium chloride & $\mathrm{LiCl}$ & $11 \%$ \\
Potassium acetate & $\mathrm{C}_{2} \mathrm{H}_{3} \mathrm{KO}_{2}$ & $23 \%$ \\
Magnesium chloride & $\mathrm{MgCl}_{2}$ & $33 \%$ \\
Potassium carbonate & $\mathrm{K}_{2} \mathrm{CO}_{3}$ & $43 \%$ \\
Magnesium nitrate & $\mathrm{Mg}\left(\mathrm{NO}_{3}\right)_{2}$ & $54 \%$ \\
Sodium bromide & $\mathrm{NaBr}$ & $59 \%$ \\
Ammonium nitrate & $\mathrm{NH}_{4} \mathrm{NO}_{3}$ & $63 \%$ \\
Potassium lodide & $\mathrm{KI}$ & $70 \%$
\end{tabular}


Ammonium chloride

$\mathrm{NH}_{4} \mathrm{Cl}$

$80 \%$

Potassium nitrate

$\mathrm{KNO}_{3}$

$92 \%$

Potassium sulfate

$\mathrm{K}_{2} \mathrm{SO}_{4}$

$98 \%$

Deionized water

$\mathrm{H}_{2} \mathrm{O}$

$100 \%$

233

234

235

236

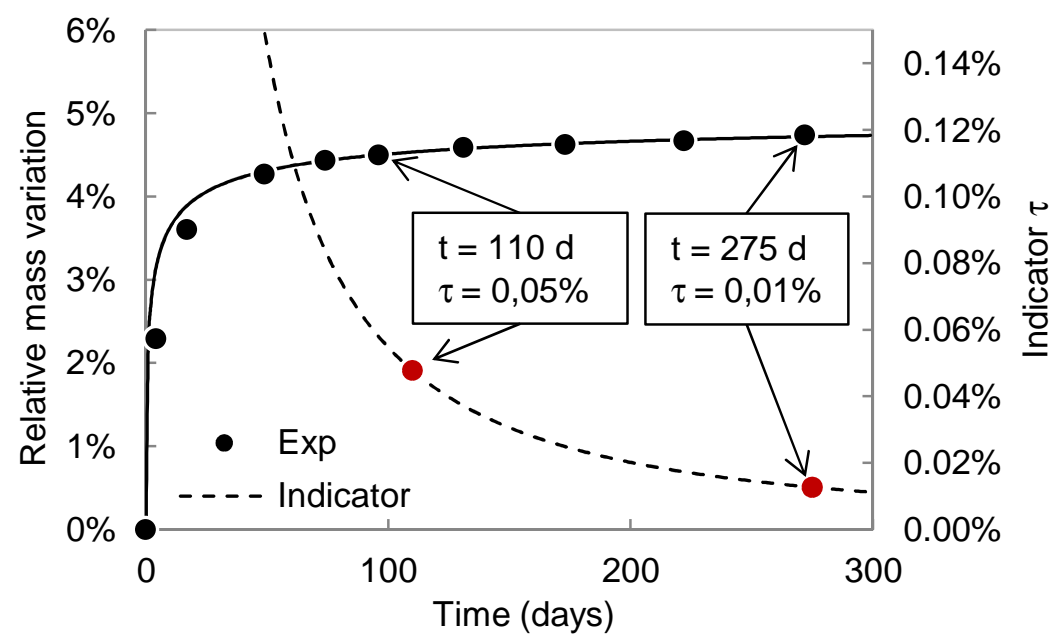

where $d_{s a t}$ is the specific gravity of the saturated paste. It was measured using the buoyancy method.

The deviation from equilibrium was characterised using an indicator $\tau$ defined as:

$$
\tau(t)=\frac{\left(\frac{\Delta m}{m}\right)_{t+1}-\left(\frac{\Delta m}{m}\right)_{t}}{\left(\frac{\Delta m}{m}\right)_{t}}
$$

where $\left(\frac{\Delta m}{m}\right)_{t}$ and $\left(\frac{\Delta m}{m}\right)_{t+1}$ are the relative mass variation measured at the times $t$ and one day after respectively. Once the indicator $\tau$ became lower than $0.05 \%$, the equilibrium was considered achieved. For instance, in the case of carbonated $\mathrm{PI}$ at $43 \% \mathrm{RH}$ (Figure 4), the criterion was reached after 110 days. After 275 days, the indicator $\tau$ reached $0.01 \%$ (five time lower than the criterion) but the difference between the relative mass variations at 110 and 275 days remained very limited: about $3.5 \%$ (relative value). 
Complementary tests were conducted using a sorption balance (SMS DVS Advantage) [10, 61]. This

The specific surface area $\left(S_{S}\right)$ was assessed using the well-known BET model $[62,63]$ :

$$
w(h)=\frac{C w_{m} h}{(1-h)[1+(C-1) h]}
$$

258 device presents two major benefits: ( $I$ ) a complete desorption isotherm could be obtained in about ten days and (ii) it allowed testing some specific $\mathrm{RH}$ values that are difficult to achieve using saturated salt solutions (especially $\mathrm{RH}$ lower than $30 \%$ ). A few disks were crushed and then powdered (sieved to remove the particles larger than $100 \mu \mathrm{m}$ ) in $\mathrm{C}_{\mathrm{CO}_{2}}$-free glove box. The powder was resaturated using deionized water: a sample of about $50 \mathrm{mg}$ was taken and introduced into the sorption balance. The tests were performed at $25^{\circ} \mathrm{C} \pm 0.1^{\circ} \mathrm{C}$ and the $\mathrm{RH}$ was decreased by steps under the "dm/dt" mode (the software automatically shifted from one $\mathrm{RH}$ step to another when equilibrium was considered to be reached).

where $C$ and $w_{m}$ are the two BET parameters. $C$ is related to the energy of the first layer and $w_{m}$ represents the water content needed to complete a monomolecular layer. The specific surface area $\left(S_{S}\right)$ was calculated using the BET monolayer parameters $w_{m}$ following [64]:

$$
S_{S}=N_{A} \frac{w_{m} A}{\rho V}
$$

where $N_{A}$ is Avogadro's number, $V$ is the molar volume of water vapour and $A$ is the surface occupied by one molecule of liquid water obtained following $[65,66]$ :

$$
A=1.091 \frac{M}{N_{A} \rho}
$$

\subsection{Permeability}

\subsubsection{Inverse analysis}

The intrinsic permeability $(K)$ was fitted through numerical simulations to match experimental data [26, 67]. Here, initially saturated specimens $(\varnothing 50 \times 100 \mathrm{~mm})$ were submitted to $55 \% \mathrm{RH}$ and $25^{\circ} \mathrm{C}$ in a climatic chamber during 100 days. The finite-element code Cast $3 m^{1}$ was used to solve eq. (3). The relative permeability to liquid water $k_{r}$ was evaluated using the Mualem-van Genuchten model [68, 69]. The water retention curves were fitted using the equation proposed by van Genuchten:

\footnotetext{
${ }^{1}$ http://www-cast3m.cea.fr/changelang.php?lang=en
} 


$$
w=w_{\text {sat }}\left[1+\left(\frac{P}{P_{0}}\right)^{\frac{1}{1-m}}\right]^{-m}
$$

270 where $P_{0}$ and $m$ are the two positive parameters of the model and $w_{\text {sat }}$ is the water content at

271 saturation $(\mathrm{RH}=100 \%)$. The relative permeability $k_{r}$ was calculated using Mualem's model (the value 272 of the parameters $P_{0}$ and $m$ are the same as above) [69]:

$$
k_{r}=\left[1+\left(\frac{P}{P_{0}}\right)^{\frac{1}{1-m}}\right]^{-m p}\left\{1-\left(\frac{P}{P_{0}}\right)^{\frac{1}{1-m}}\left[1+\left(\frac{P}{P_{0}}\right)^{\frac{1}{1-m}}\right]^{-m}\right\}^{2}
$$

273 where the exponent $p$ is known as the pore-interaction factor (without unit) and embodies pore

274 tortuosity. It was taken equal to +0.5 as suggested by Mualem [68], but $p$ may be negative or positive 275 [68].

276 The moisture capacity (the left-hand term $\emptyset\left(\frac{\partial S}{\partial P}\right)$ in eqs. 3 and 5) was then:

$$
\varnothing\left(\frac{\partial S}{\partial P}\right)=\frac{m \emptyset}{(m-1) P_{0}}\left(\frac{P}{P_{0}}\right)^{\frac{1}{1-m}}\left[1+\left(\frac{P}{P_{0}}\right)^{\frac{1}{1-m}}\right]^{-1-m}
$$

277 The numerical restitution (solid line) of the experimental relative mass loss (circles) is illustrated on

278 Figure 5 (a). The value of $K$ is estimated by minimization of the quadratic difference between the 279 computed and measured relative mass loss for each measuring time (Figure $5 \mathrm{~b}$ ). The minimum yielded the value of the intrinsic permeability. In this example (non-carbonated $\mathrm{PI}$ ), the optimal value of $K$ was equal to $2.7 \times 10^{-22} \mathrm{~m}^{2}$.

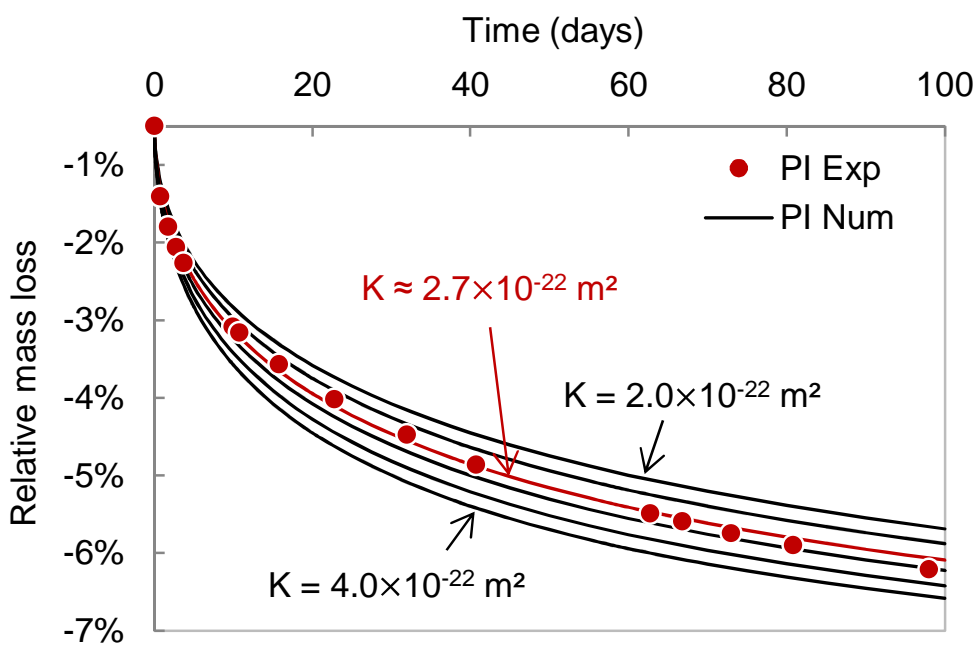

(a)

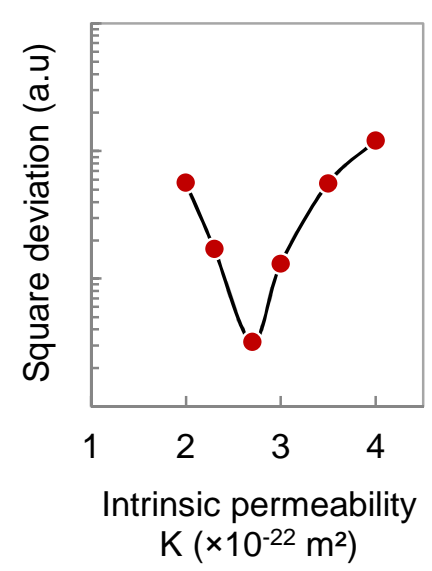

(b) 

permeability $K$ (non-carbonated PI) and (b) Evolution of the quadratic deviation as a function of the intrinsic permeability $K$.

285

286

Inverse analysis was used for non-carbonated specimens only. The carbonated ones were too small (the specimens dry too quickly and the mass loss is too low to yield appropriate results) and another approach had to be used to assess permeability.

\subsubsection{Cup-method}

The cup-method [70] is a direct way of determination of the effective permeability. In this experiment, disks do constitute a boundary separating two different environments (same temperature but two different RH: $h_{1}$ and $h_{2}$ ) through which water is transported (Figure 6)
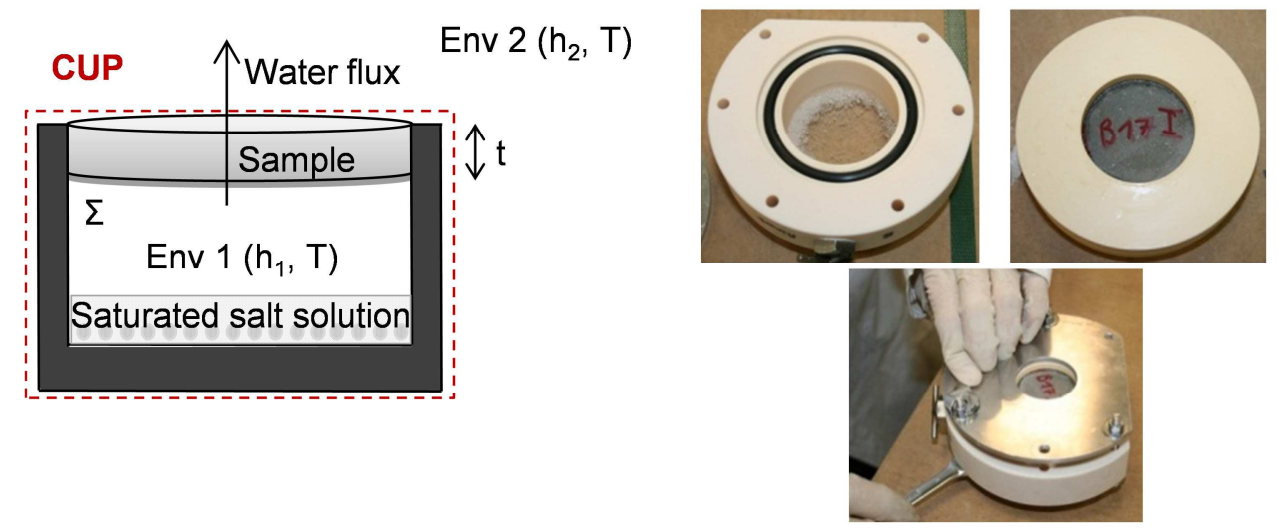

Figure 6 : Sketch and photos of the cup-method set up.

The permeability was assumed to be constant on the $\mathrm{RH}$ range $\left[h_{1} ; h_{2}\right]$. In steady state, Darcy's law allows estimating the effective permeability $K_{e}$ based on the mass loss measurement (Figure 7):

$$
K_{e}=-\frac{\dot{m} \eta}{\rho \Sigma \frac{\Delta P}{t}} \quad \text { and } \quad \Delta P=-\rho \frac{R T}{M} \ln \left(\frac{h_{1}}{h_{2}}\right)
$$

where $\dot{m}$ is the mass loss time derivative $[\mathrm{kg} / \mathrm{s}], \Sigma$ the disk cross sectional area [m²], $t$ the thickness [m], $\Delta P$ the liquid pressure difference between the two environments (computed using eq.14) [Pa]. 


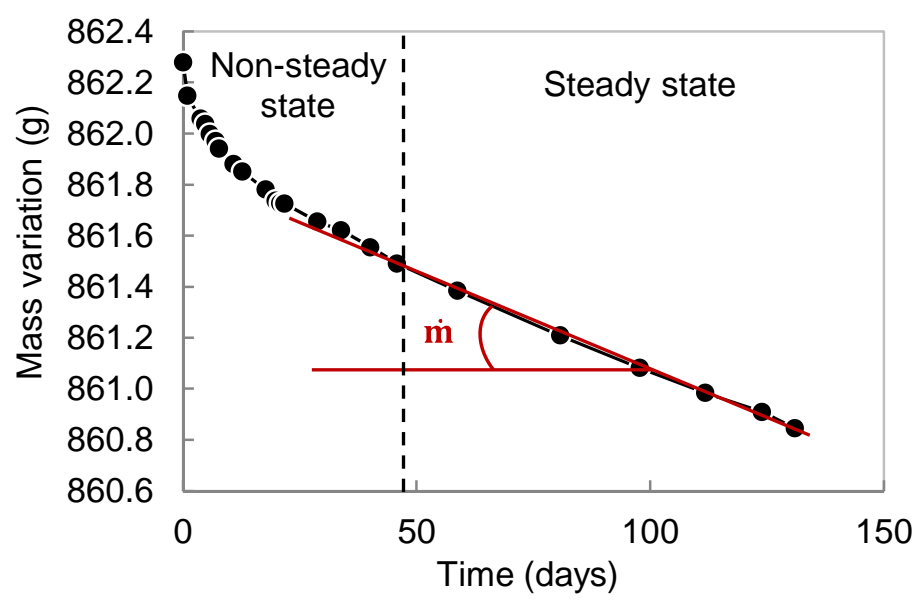

Figure 7 : Cup mass evolution (PI disk) vs. time for a $64 \%\left(h_{1}\right)-55 \%\left(h_{2}\right) \mathrm{RH}$ range at $25^{\circ} \mathrm{C}$

An experimental set-up was implemented by adapting existing diffusion cells (Figure 6). In practice, $h_{1}$ was controlled using a saturated salt solution whereas $h_{2}$ was controlled using a climatic chamber (which also allows controlling temperature). In this test, initially saturated samples are used to focus on the drying path (and $h_{1}$ was always greater than $h_{2}$ ). The cup-method is implemented on carbonated disks (due to the small specimen thickness) as well as non-carbonated ones to validate the method.

\subsection{Cracking}

Because cracks were observed on the disks surface after carbonation, some of them were impregnated with a fluid resin incorporating a fluorescent dye ${ }^{2}$. The disks were observed in the light of a ultra-violet (UV) lamp. The resin-filled cracks could clearly be seen thanks to the dye fluorescence. Pictures were taken and then processed using a specific software ${ }^{3}$ in order to provide a cracking index $\left(I_{C}\right)$ to compare qualitatively the pastes (grey-scale image processing). The cracking index was simply defined as the ratio of the number of pixels attributed to the cracks to the total number of pixels of the disk surface:

$$
I_{C}=\frac{\text { Number of pixels attributed to the cracks }}{\text { Total number of pixels of the surface }}
$$

\footnotetext{
${ }^{2}$ Struers EpoDye and EpoFix

${ }^{3}$ http://imagej.nih.gov/ii/
} 


\section{Results}

\subsection{Mineralogical changes}

315 The usual mineralogical changes could be highlighted using XRD (Figure 8): dissolution of the main 316 hydrates (portlandite, AFt and AFm) and precipitation of calcium carbonate (calcite and vaterite, the 317 presence of aragonite was not identified). These evolutions were supported by the TGA data (Figure 318 9). 100 days were necessary to achieve a stabilized state of carbonation (constant concentration of 319 calcium carbonate). As it was expected, the amount of calcium carbonate increased with the initial portlandite content. The remaining presence of portlandite was also observed after carbonation that was attributed to the calcium carbonate formation around the portlandite crystal inhibiting their dissolution [71-74].

Figure 10 presents the results obtained using ${ }^{29} \mathrm{Si} N \mathrm{NR} . \mathrm{Q}_{0}$ represents isolated $\mathrm{SiO}_{2}$ tetrahedra, $\mathrm{Q}_{1}$ denotes chain end groups, $Q_{2}$ middle groups, $Q_{3}$ branching sites and $Q_{4}$ cross-linking ones [48]. $Q_{2}{ }^{p}$ represents the bridging $\mathrm{SiO}_{2}$ sites but other tetrahedra cannot be distinguished using ${ }^{29} \mathrm{Si}$ MAS NMR. A more detailed analysis would be required to describe accurately the C-S-H structure $[51] .{ }^{29} \mathrm{Si} \mathrm{NMR}$ spectra showed that carbonation decreases the amount of anhydrous phases $\left(Q_{0}\right)$ in agreement with the XRD results. But above all this, the characteristic peaks of the C-S-H $\left(Q_{1}, Q_{2}{ }^{p}\right.$ and $\left.Q_{2}\right)$ drastically decreased revealing significant decalcification of the C-S-H. The end result was close to a silicate material $\left(Q_{3 \text { gel }}\right.$ and $Q_{4}$ gel $)$ which could possibly contain calcium (Ca-enriched silica gel with a low $C / S$ ratio).
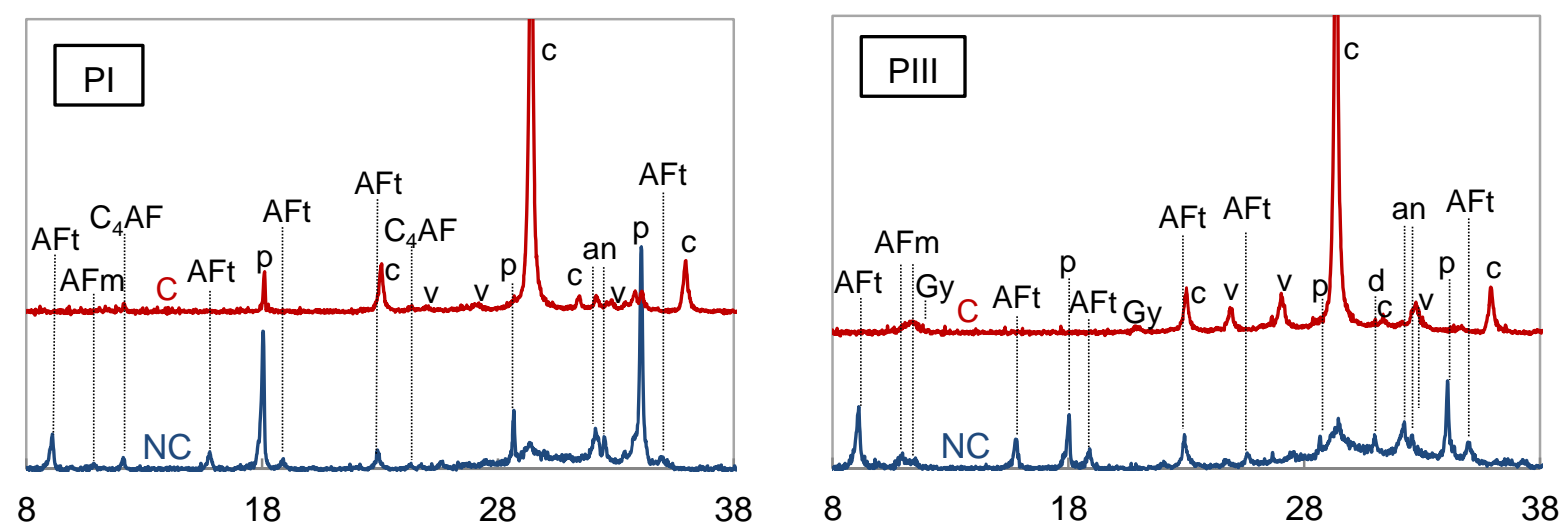

$38 \quad 8$

18

28 

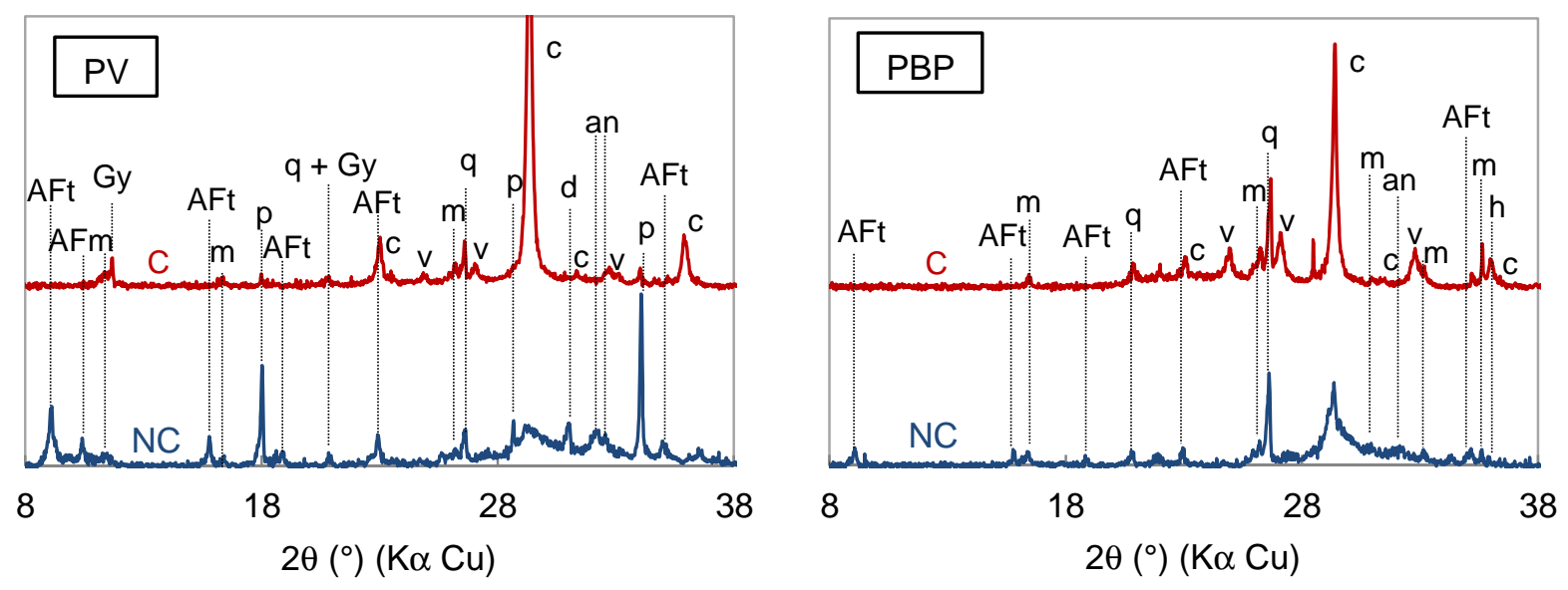

Figure 8: X-ray diagrams acquired for non-carbonated (NC) and carbonated (C) pastes PI, PIII,

PV and PBP - AFt: ettringite, AFm: monosulfate, m: mullite, p: portlandite, q: quartz, Gy:

gypsum, c: calcite, v: vaterite, a: aragonite, d: dolomite, an: anhydrous phases $C_{2} S$ and $C_{3} S, h$ :

hematite.
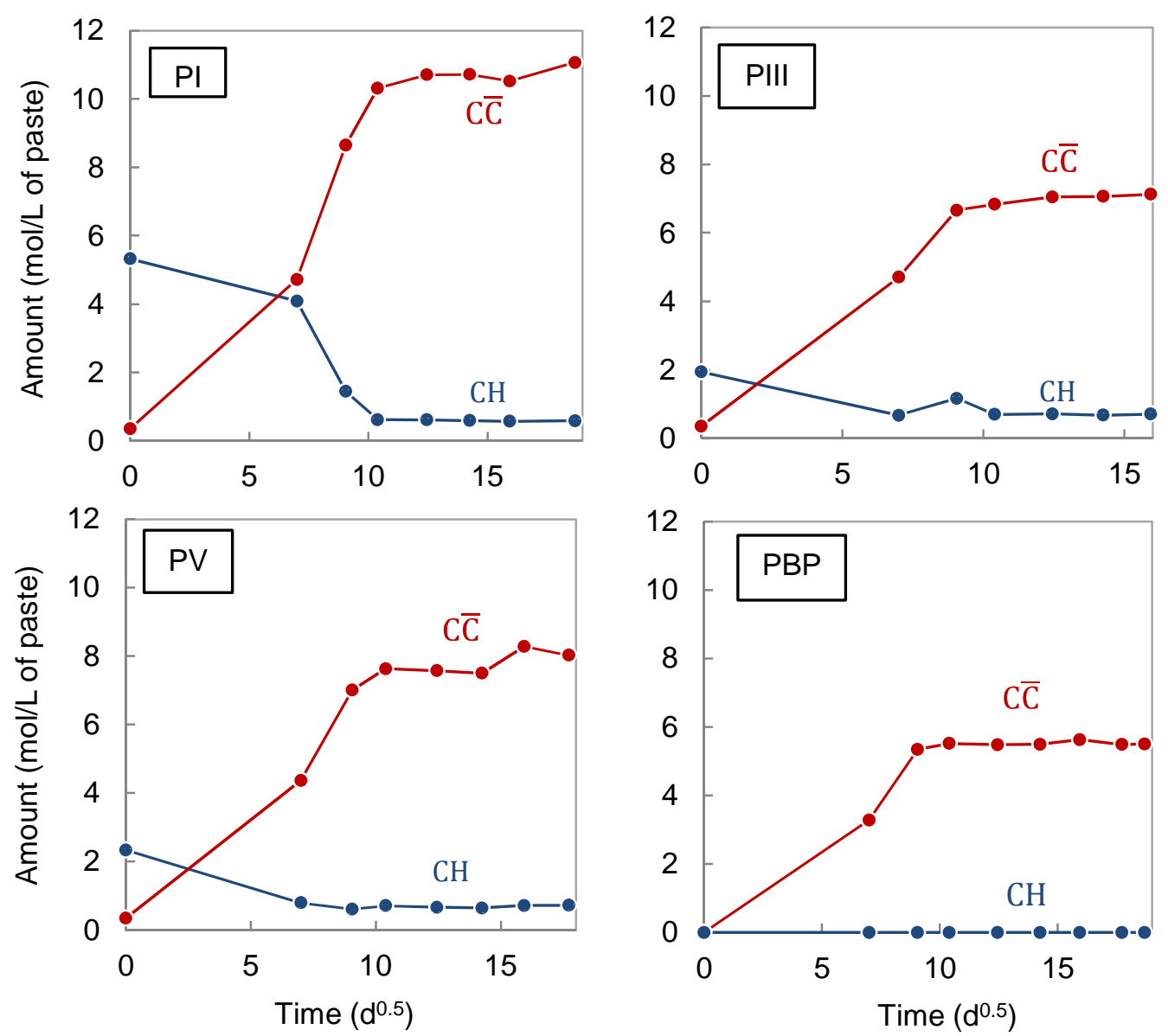

Figure 9: Evolution of the amounts of portlandite $(\mathrm{CH})$ and calcium carbonate $(\mathrm{C} \overline{\mathrm{C}})$ as a function of carbonation time in PI, PIII, PV and PBP. 

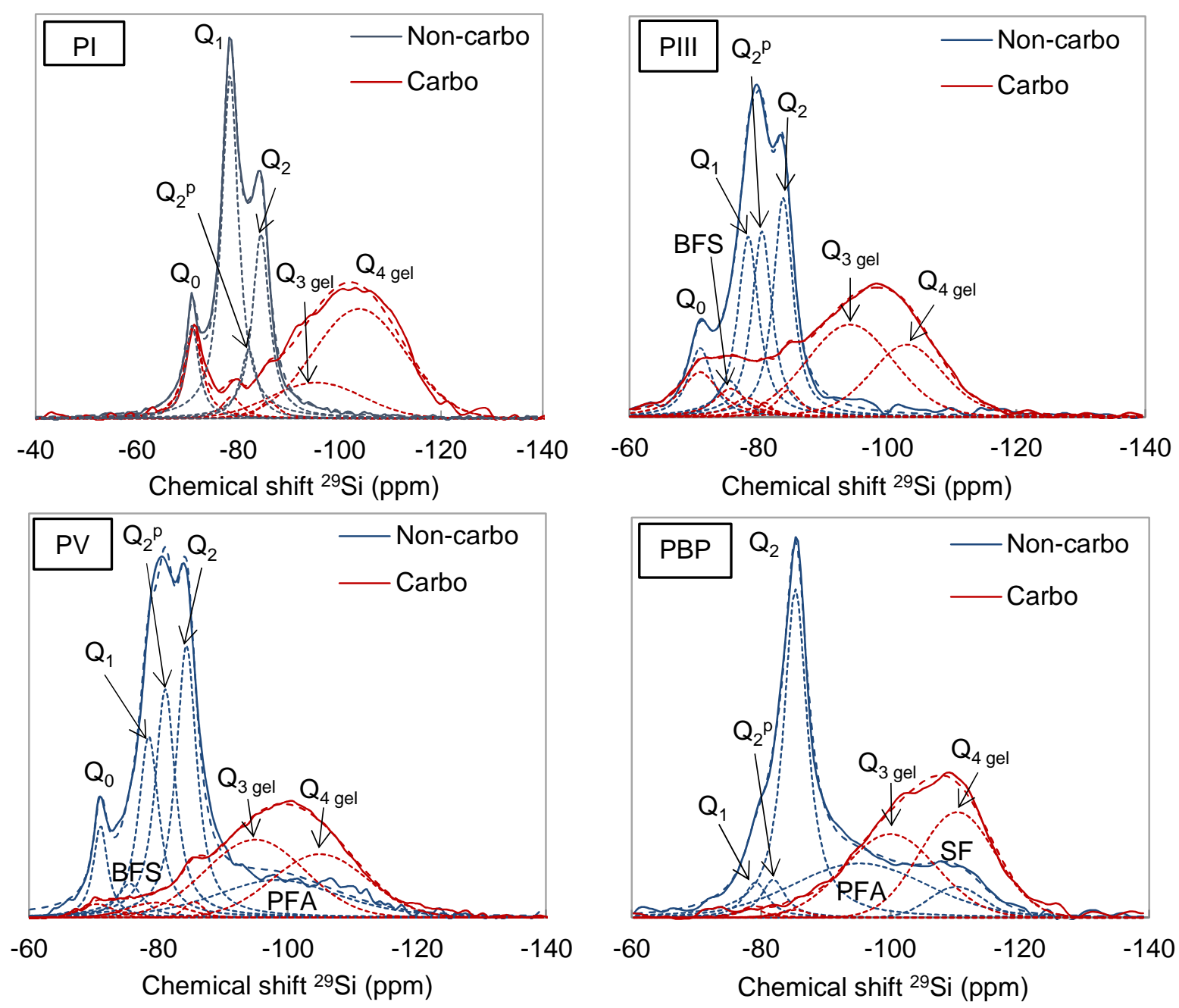

Figure 10: ${ }^{29}$ Si MAS NMR spectra of PI, PIII, PV and PBP.

Many disks were cracked or even broken at the end of the carbonation campaign, regardless of the composition: more than $50 \%$ of the PI specimens and to a lesser extent PIII, PV and PBP (between $25 \%$ and $40 \%$ ). This was believed to be due to the combination of drying and carbonation shrinkage.

Only the unbroken and non-cracked disks (as observed with the naked eyes) were used for further characterization.

\subsection{Porosity}

The precipitation of calcium carbonate led to the reduction of water porosity (Table 4). The fall of porosity was of the same order of magnitude of those obtained by Ngala and Page [5]. The porosity variation was directly related to clinker substitution by pozzolanic additions: the higher the initial portlandite content, the higher the fall of porosity (Figure 9 and Table 4). 


\begin{tabular}{cccccc} 
& & PI & PIII & PV & PBP \\
\cline { 3 - 6 } Water content $w_{\text {sat }}$ & Non-carbonated & $22.1 \%$ & $26.2 \%$ & $25.2 \%$ & $30.6 \%$ \\
& Carbonated & $10.0 \%$ & $14.8 \%$ & $14.1 \%$ & $20.0 \%$ \\
\hline \multirow{2}{*}{ Porosity } & Non-carbonated & $36.3 \%$ & $39.8 \%$ & $36.9 \%$ & $41.0 \%$ \\
& Carbonated & $21.1 \%$ & $29.3 \%$ & $27.6 \%$ & $35.5 \%$ \\
& Variation & $-15.2 \%$ & $-10.5 \%$ & $-9.3 \%$ & $-5.5 \%$ \\
\hline
\end{tabular}

352 Not only the total porosity was reduced but also the pore size distribution was modified (Figure 11).

353 The critical pore diameter decreased for PI and PV whereas a slight, but significant, coarsening of the 354 pore structure was observed for PIII and PBP.
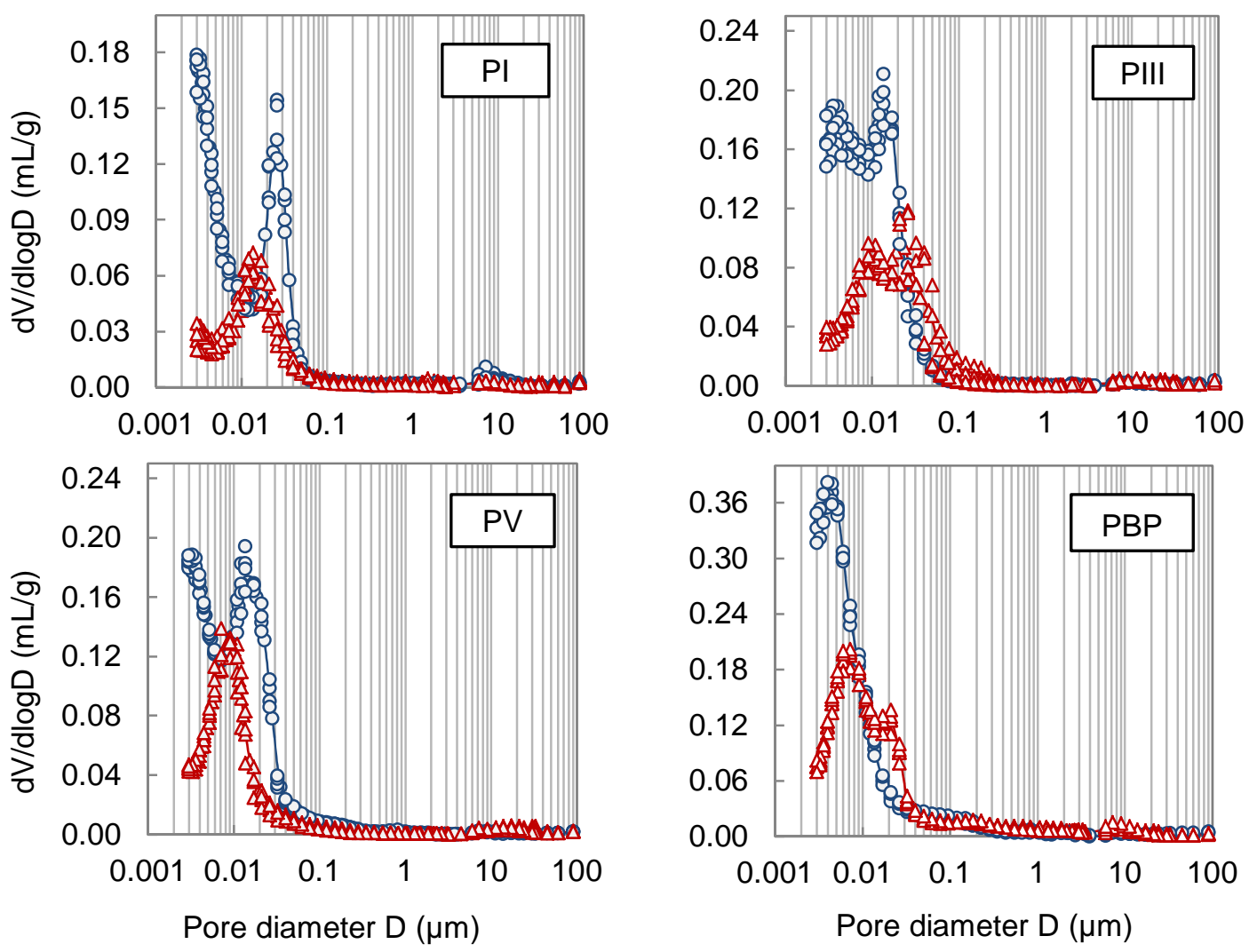

Figure 11: Impact of carbonation on the pore size distribution (characterized by MIP two samples per formulation).

\subsection{Water desorption isotherm}

Figure 12 presents the water desorption isotherms obtained using the desiccator method (filled circles) 
was then obtained for all the binders in the non- and carbonated states. Carbonation led to a significant drop of water content at equilibrium that was directly related to porosity clogging (Table 4).

The desorption isotherms morphology was also altered as a consequence of the pore size distribution modification. This is patent when saturation is used to plot the water retention curves (Figure 13). As already beheld by Houst and Whittmann [4], the modifications of the CEM I paste curve appeared moderate and remained limited to low $\mathrm{RH}$. Those of the blended pastes were more significant and appeared to be all the more significant as the amount of addition was high.

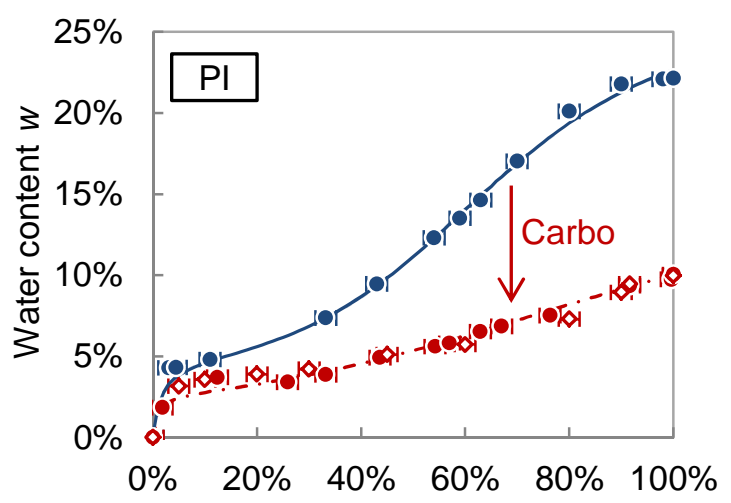

$\mathrm{RH}$

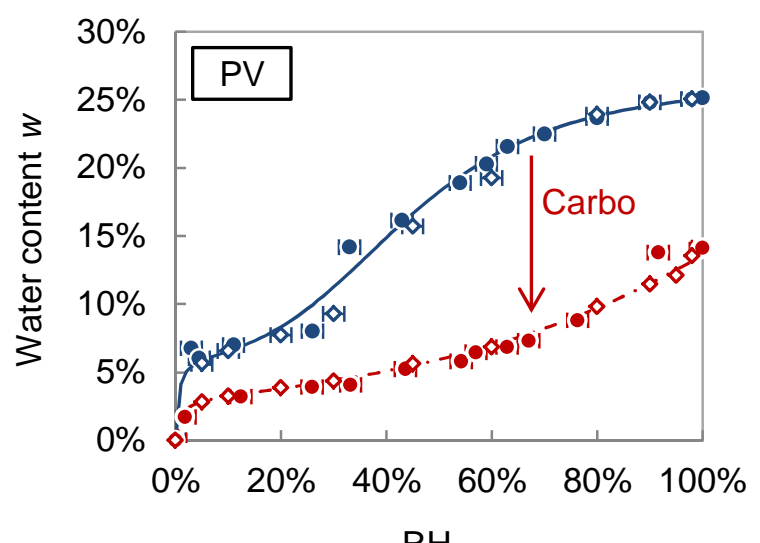

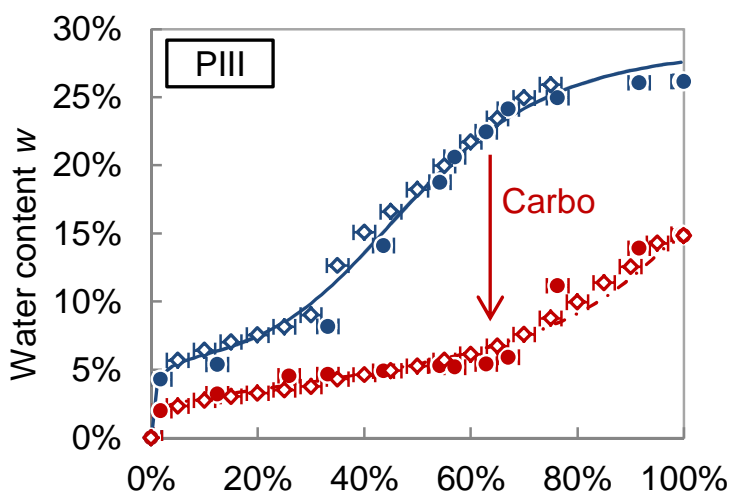

$\mathrm{RH}$

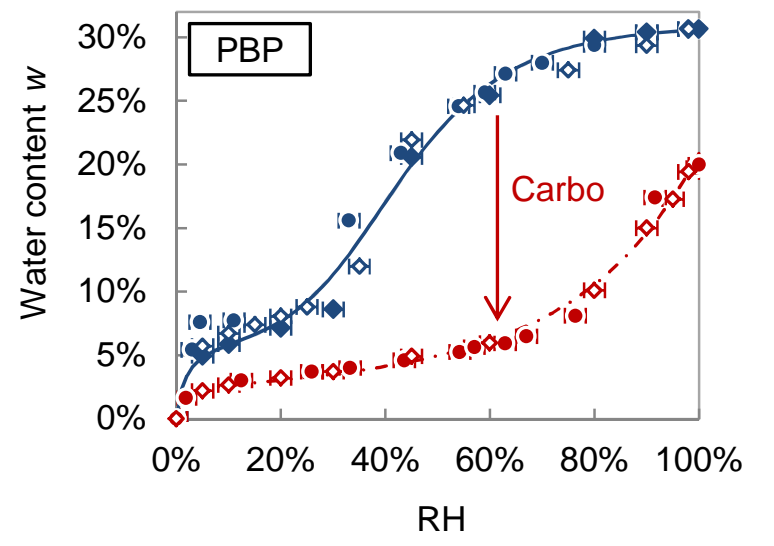

Figure 12: Water retention curves of the hardened cement pastes (water content). The lines are guides for the eyes only.

The van Genuchten parameters needed for the inverse analysis (pressure $P_{0}$ and exponent $m$ ) were evaluated; the results are presented on Figure 13 and the parameters are listed on Table 5. 

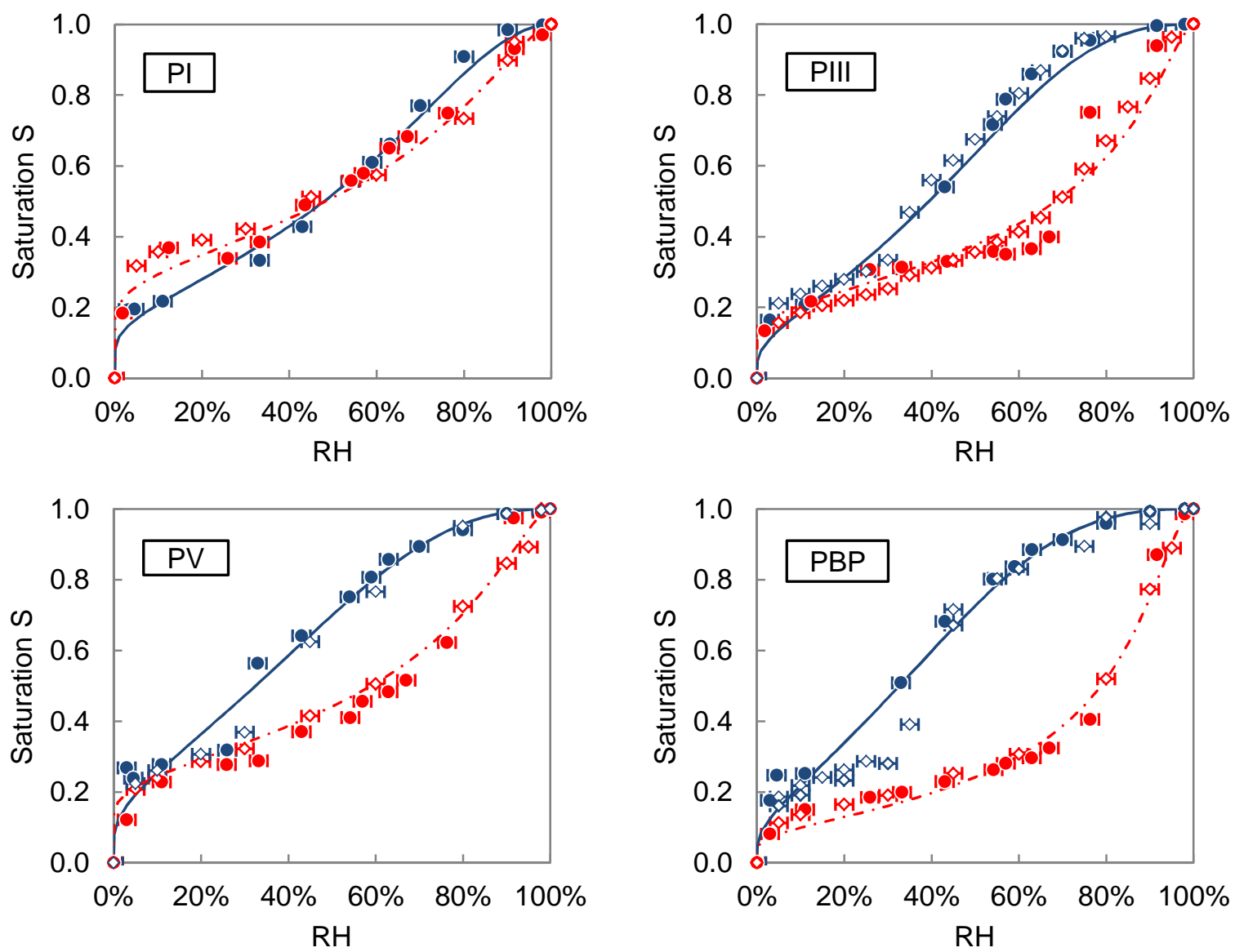

\begin{tabular}{ccccccccc}
\hline & \multicolumn{2}{c}{ PI } & \multicolumn{2}{c}{ PIII } & \multicolumn{2}{c}{ PV } & \multicolumn{2}{c}{ PBP } \\
\cline { 2 - 9 } & $P_{0}$ & $m$ & $P_{0}$ & $m$ & $P_{0}$ & $m$ & $P_{0}$ & $m$ \\
\hline Non-carbo & 51.4 & 0.46 & 86.5 & 0.56 & 96.9 & 0.53 & 108.7 & 0.58 \\
Carbo & 26.8 & 0.33 & 14.9 & 0.34 & 20.8 & 0.34 & 14.9 & 0.43 \\
\hline
\end{tabular}

Figure 13: Water retention curves of the hardened cement pastes (saturation). The lines correspond to van Genuchten model (eq. 11).

Table 5: The van Genuchten parameters ( $P_{0}$ in MPa and $m$ without unit) obtained by capillary-pressure curve fitting.

377 Carbonation led to a reduction of the specific surface area (Table 6). Using the approach proposed by

378 Olson and Jennings [47] together with the desorption isotherm (water content at $20 \% \mathrm{RH}$ ), the C-S-H

379 content was estimated (

380 Table 7). It was then implicitly assumed that this approach remains valid for carbonated cementitious materials. It was found that $\Delta S_{S}$ increased with $\Delta \mathrm{C}-\mathrm{S}-\mathrm{H}$ indicating $\mathrm{C}-\mathrm{S}-\mathrm{H}$ carbonation and partial dissolution. 
Table 6: Impact of carbonation on the specific surface area $\left(S_{S}\right)$.

\begin{tabular}{ccccc}
\hline$S_{S}\left(\mathrm{~m}^{2} / \mathrm{g}\right)$ & $\mathrm{PI}$ & $\mathrm{PIII}$ & $\mathrm{PV}$ & $\mathrm{PBP}$ \\
\hline Non-carbonated & 190 & 300 & 298 & 382 \\
Carbonated & 93 & 89 & 98 & 88 \\
$\Delta S_{S}$ & -97 & -211 & -200 & -294 \\
\hline
\end{tabular}

Table 7: Impact of carbonation on the C-S-H content.

\begin{tabular}{ccccc}
\hline C-S-H concentration (mol/L of paste) & PI & PIII & PV & PBP \\
\hline Non-carbonated & 5.2 & 6.5 & 6.5 & 7.6 \\
Carbonated & 3.7 & 3.3 & 3.9 & 2.6 \\
$\Delta$ C-S-H & -1.4 & -3.2 & -2.5 & -5.0 \\
\hline
\end{tabular}

386

\subsection{Cracking}

388 Figure 14 presents the pictures of the non- and carbonated disks surface. The absence of cracks on

389 the non-carbonated disks could be noticed whereas the carbonated ones were more or less

390 significantly cracked depending on the considered binder. Although only the disks surface could be

391 observed, the resulting cracking pattern was believed to be representative of that of the bulk. The image processing results are reported on Figure 14 ("thresholded" binary image) and in Table 8

393 (cracking index values). An average crack opening of 10-15 $\mu \mathrm{m}$ was measured for all the binders.

394 Different values of the cracking index were found depending on the considered binder: PI presented the lowest value and PBP the highest. 

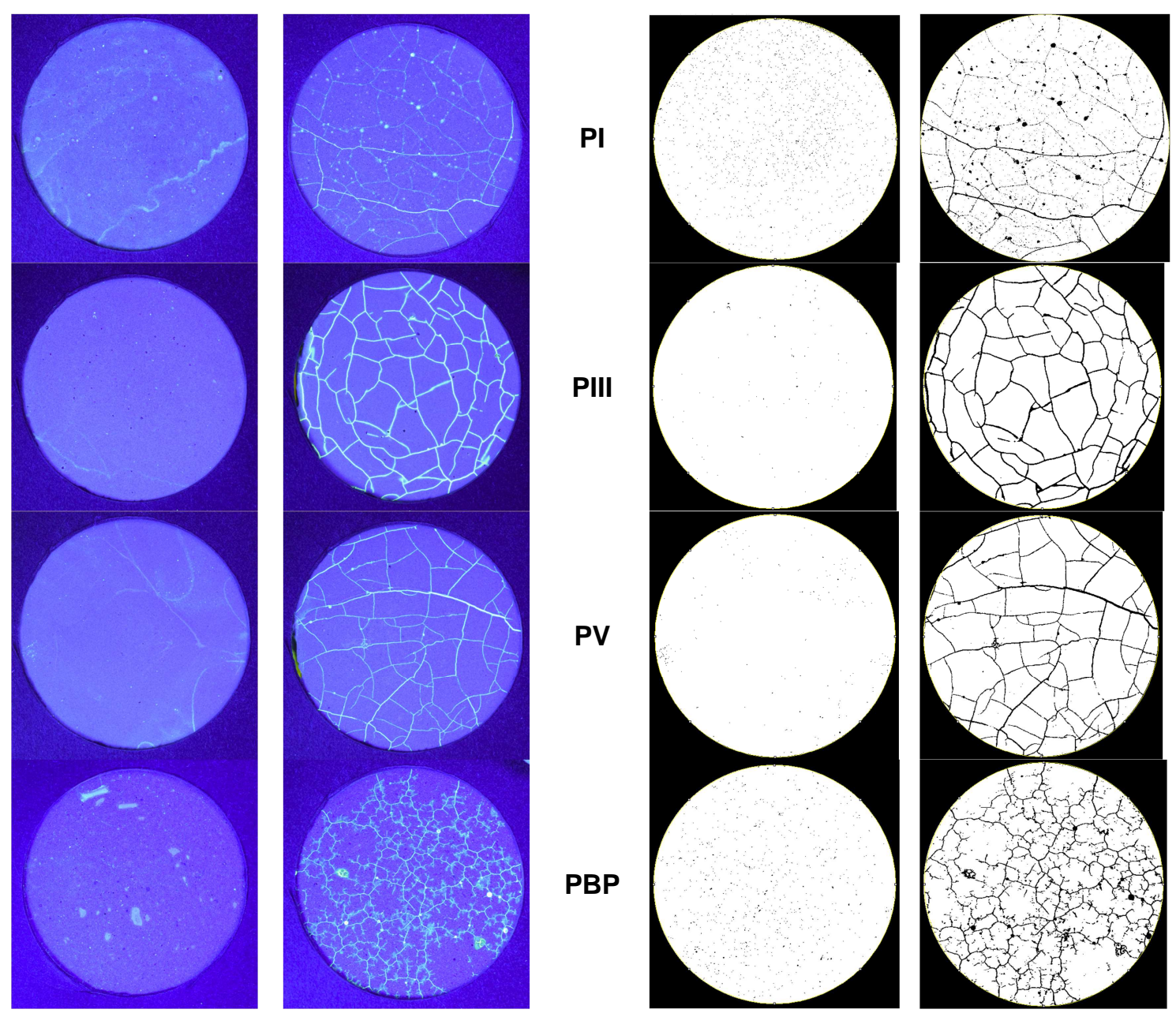

Figure 14: Photos of the non- and carbonated impregnated disks under UV light (on the left) and result of the image processing (on the right)

Table 8: Cracking indices $\left(I_{C}\right)$.

\begin{tabular}{lllll} 
& PI & PIII & PV & PBP \\
\cline { 2 - 5 } & $4 \%$ & $9 \%$ & $7 \%$ & $10 \%$ \\
\hline
\end{tabular}

\subsection{Permeability}

\subsubsection{Inverse analysis}

The numerical restitution of the experimental drying kinetics of the $\varnothing 50 \times 100 \mathrm{~mm}$ cylinders $(55 \% \mathrm{RH}$ and $25^{\circ} \mathrm{C}$ ) is presented on Figure 15 (following the method presented in part 4.4.1). The obtained intrinsic permeability values are compiled in Table 9. These values are consistent with the pore size distributions: the finer the pore size distribution, the lower the permeability value. 


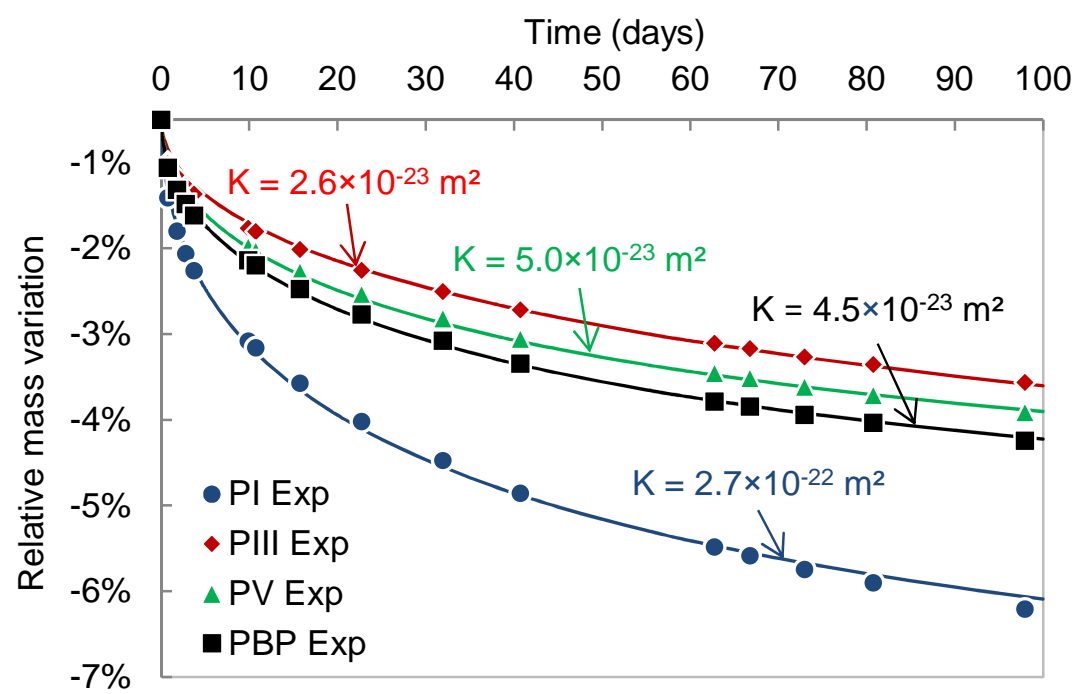

\begin{tabular}{lcccc}
\hline & PI & PIII & PV & PBP \\
\hline$K_{n c}\left(\times 10^{-22} \mathrm{~m}^{2}\right)$ & 2.70 & 0.26 & 0.50 & 0.45 \\
\hline
\end{tabular}

Figure 15: Numerical restitutions of the relative mass loss as a function of the intrinsic permeability (K) (PI, PIII, PV and PBP).

Table 9: Values of the intrinsic permeability $(K)$ of non-carbonated paste.

412 Firstly, the cup-method was applied on non-carbonated PI to compare with inverse analysis (Figure

413 16). A good agreement between both methods was noticed: the two datasets presented the same

414 order of magnitude and described a similar trend. A small difference could however be observed that 415 could be due to:

416 - the variability linked to the differences between the batches used for the two methods (the data

417 required for inverse analysis were extracted from a previous study [33],

418 - uncertainties on the unsaturated properties (for instance water retention curve),

419 - the error on the relative permeability $\left(k_{r}\right)$ assessed using Mualem's model and more specifically 420 the value of the pore interaction factor $p$ (eq. 12) $[68,75,76]$. 
Saturation $S$

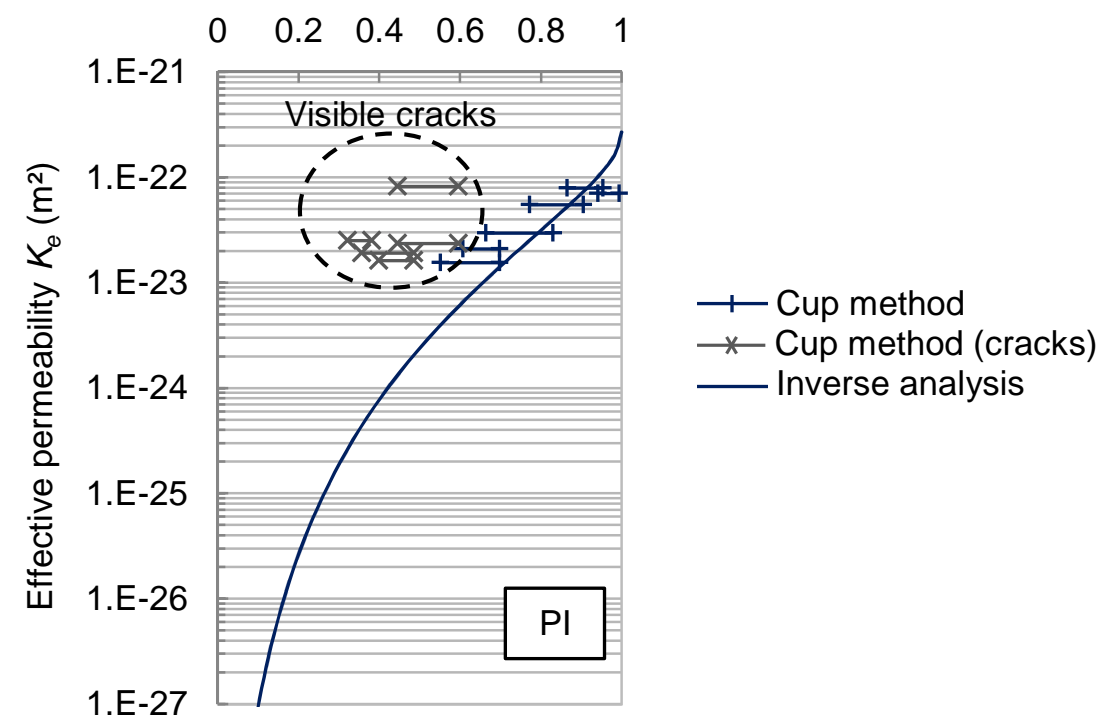

421

422

423 It was noticed that for $\mathrm{RH}$ lower than $40 \%$, a permeability increase was obtained for the non-

424

425

426

427

428

429

430

431

432

Figure 16: Effective permeability $\left(K_{e}\right)$ evolution vs. saturation state $(S)$, at $25^{\circ} \mathrm{C}$, for noncarbonated PI.

carbonated specimens. Cracks could be observed on the disk surface. They were believed to be due to restrained drying shrinkage. Beyond that, the authors think that the comparison was globally satisfactory and that the cup method is an efficient tool for unsaturated permeability evaluation. This statement could not however be generalized to the blended cements (Figure 17) for which the reliable permeability description was limited to a small range of saturation (around 0.8 to 1.0 ). This was due to their refined pore size distribution leading to flattened desorption isotherms at high $\mathrm{RH}$ (Figure 12). In the following sections, the permeability of non-carbonated blended cement pastes was then described using inverse analysis. 


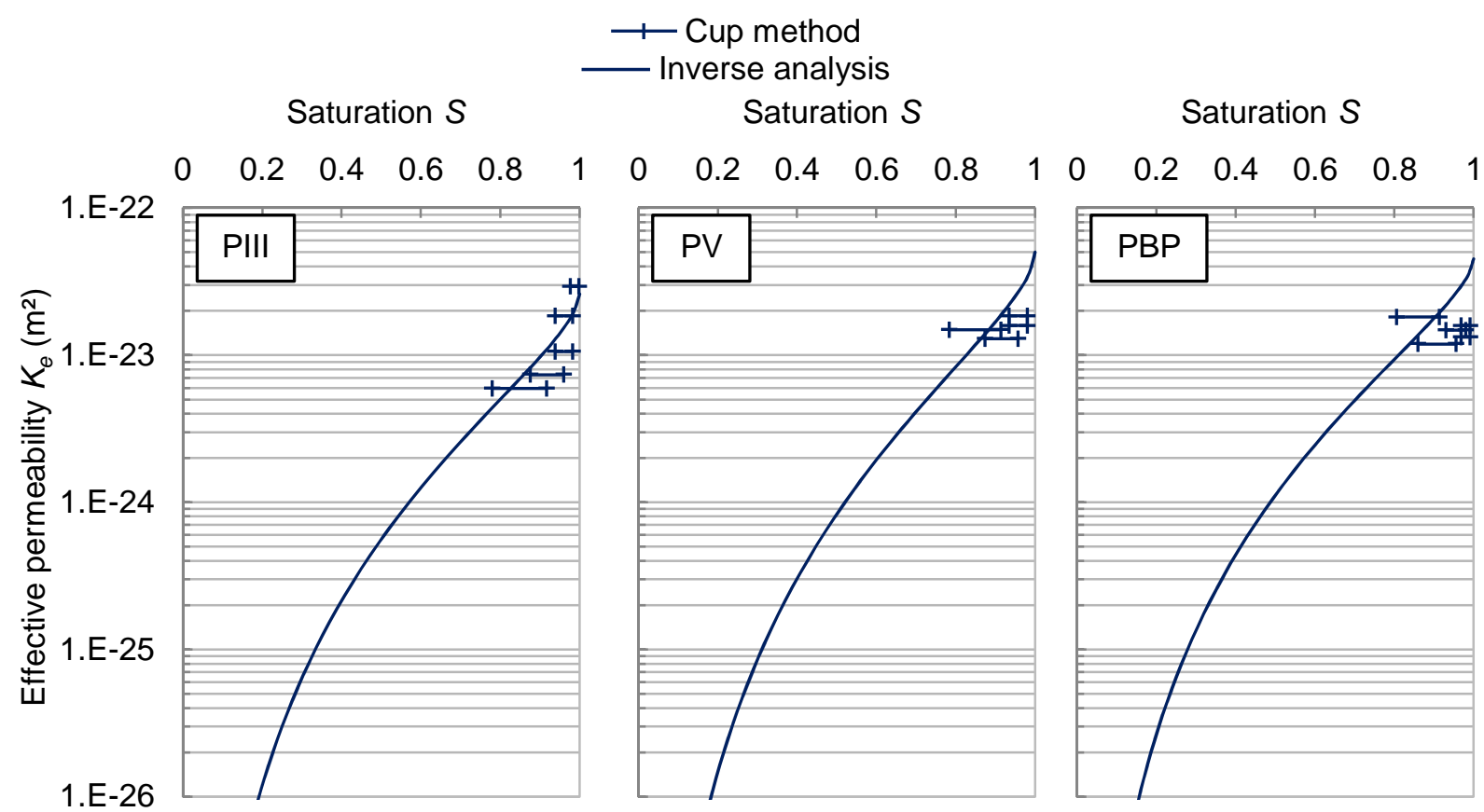

Figure 17: Effective permeability $\left(K_{e}\right)$ evolution vs. saturation state $(S)$, at $25^{\circ} \mathrm{C}$, for noncarbonated PIII, PV and PBP.

435 The cup-method was applied to assess the unsaturated permeability of the carbonated pastes (Figure 18). A decrease in the permeability of PI was observed subsequently to carbonation that is consistent with porosity clogging. On the opposite side, a significant increase of permeability was found for the blended cements despite the fall of porosity. 
Saturation $S$

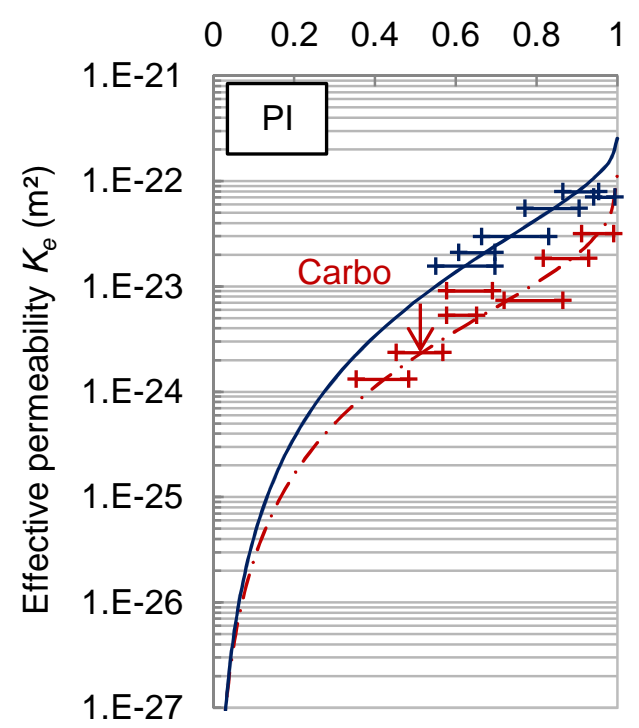

Saturation $S$

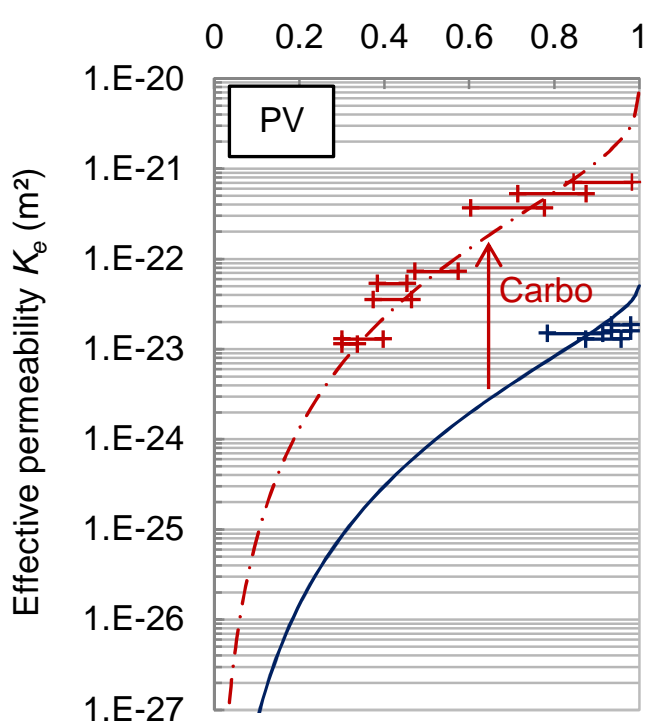

Saturation $S$

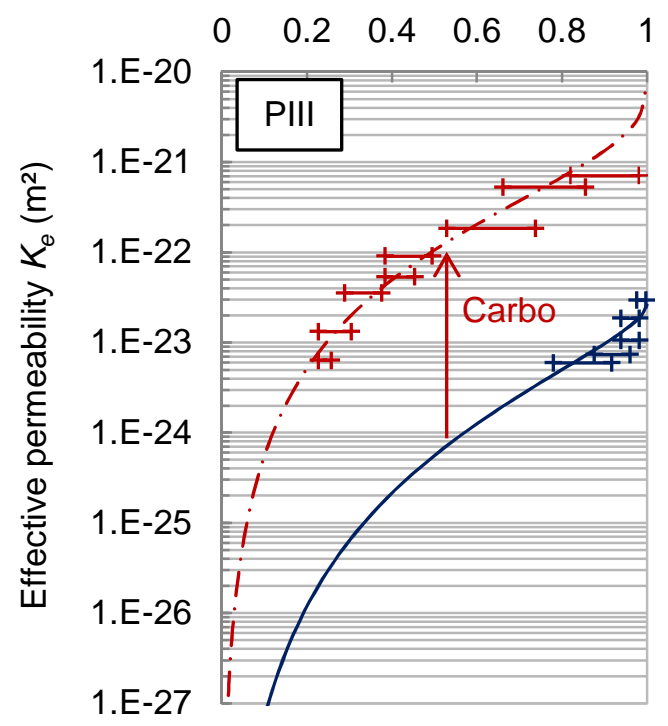

Saturation $S$

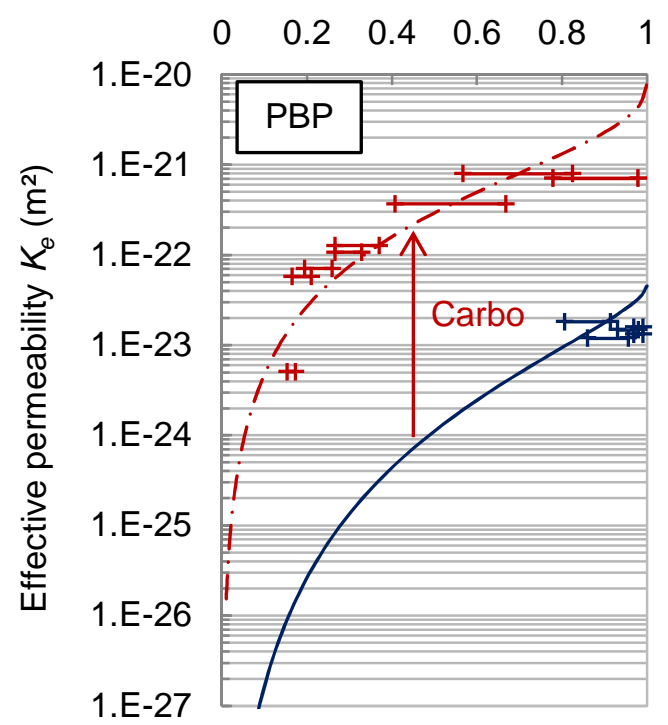

Figure 18: Impact of carbonation on the effective permeability $\left(K_{e}\right)$. The lines stand for the best

fit using Mualem-van Genuchten model (with $p \neq 0.5$ ).

Intrinsic permeability values of the carbonated pastes were assessed following eq. (16). This is the well-known Mualem-van Genuchten equation. It is the same as eq. (12) but it is expressed in terms of saturation instead of pressure. No restriction was imposed to the pore interaction factor value (the exponent $p$ ) to improve the fitting capacity [75-79]. The resulting $p$ values were different from the default value (+0.5) proposed by Mualem [68]: they were all negative as it was already observed [75, 76]. The corresponding values (pore interaction factor and intrinsic permeability) are compiled in 
Table 10.

$$
K_{e}=K_{c}^{e x p} S^{p}\left[1-\left(1-S^{1 / m}\right)^{m}\right]^{2}
$$

449

450

\begin{tabular}{ccccc}
\hline & $\mathrm{PI}$ & $\mathrm{PIII}$ & $\mathrm{PV}$ & $\mathrm{PBP}$ \\
\hline$K_{c}^{\text {exp }}\left(\times 10^{-22} \mathrm{~m}^{2}\right)$ & 1.16 & 74.82 & 74.39 & 81.48 \\
$p$ & -3.31 & -2.59 & -1.83 & -2.18 \\
\hline
\end{tabular}

Table 10: Intrinsic permeability value of the carbonated pastes.
451

452

453

454

455

Two different explanations were explored to explain the significant permeability increase of the blended cement pastes: $(i)$ coarsening of the pore structure and formation of large pores and (ii) microcracking. These points are discussed in the following section.

\section{Discussion}

The coarsening of the pore structure and formation of large pores could not be observed using MIP. Microcracking was then believed to be the major cause of the permeability increase. This was supported by the fact that the permeability of the carbonated disks increases with the cracking index $\left(I_{C}\right)$ as depicted on Figure 19 (a). $R_{K}$ is the ratio of the intrinsic permeability of the carbonated paste $K_{c}^{e x p}$ to the non-carbonated one $K_{n c}$ (Table 11):

$$
R_{K}=\frac{K_{c}^{e x p}}{K_{n c}}
$$

For $R_{K} \leq 1(\mathrm{PI})$, the high amount of calcium carbonates (due to the high initial portlandite content) led to significant porosity clogging that prevailed over the effect of microcracking. On the contrary, for $R_{K} \geq 1$ (PIII, PV and PBP), the effect of microcracking prevailed over porosity clogging. This fact was directly related to the initial mineralogical composition of the pastes. C-S-H rich pastes (with low portlandite) showed significant cracking after carbonation (Figure 19, b): the higher the initial C-S-H content, the higher the cracking index $\left(I_{C}\right)$. The authors believe that the cracking was induced by C-S-H carbonation following the proposition of Swenson and Sereda [71]. The C-S-H decalcification induced by carbonation and the subsequent polymerisation (increase of the main silica chain length) generated shrinkage [80]. This carbonation shrinkage [42, 71, 81-83] eventually led to cracking as it 


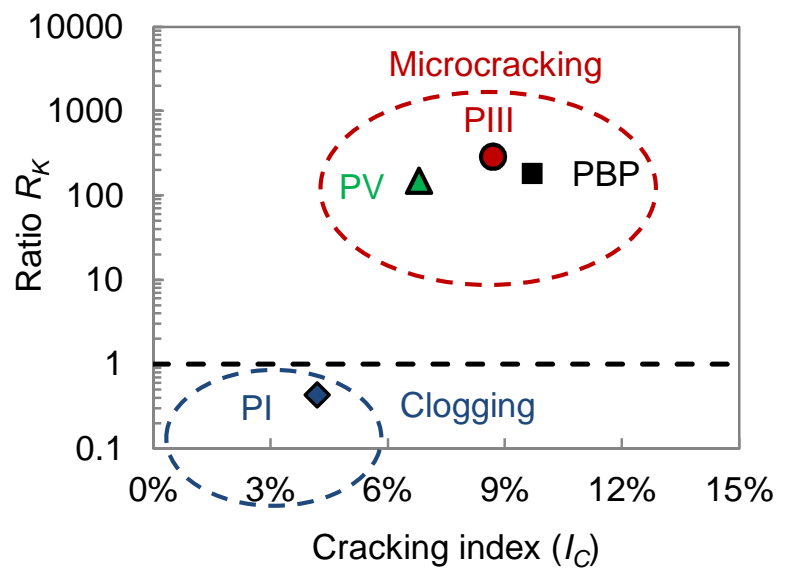

(a)

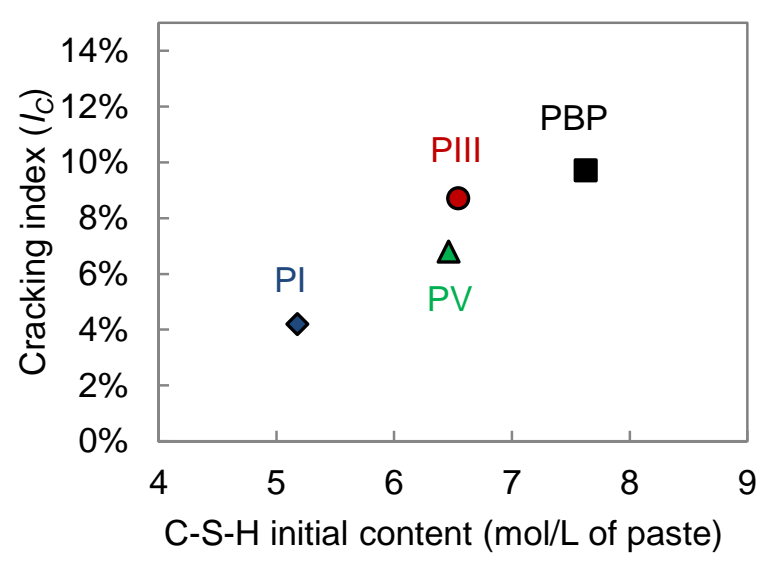

(b)

Figure 19: Influence of cracking on permeability (a) and influence of C-S-H initial content on the cracking index $\left(I_{C}\right)$.

The dataset obtained was used to describe the effect of porosity clogging on permeability. A simple law derived from Kozeny-Carman model [86-89] was used:

$$
K_{c}^{K-C}=K_{n c}\left(\frac{\emptyset_{c}}{\emptyset_{n c}}\right)^{3}\left(\frac{1-\emptyset_{n c}}{1-\emptyset_{c}}\right)^{2}
$$

where $K_{n c}, K_{c}^{K-C}, \emptyset_{c}$ and $\emptyset_{n c}$ are the intrinsic permeability and water porosity values of the non- and carbonated pastes respectively. The ratio $R_{K}$ was computed once again, but this time the permeability of the carbonated pastes was estimated using eq. (18) $\left(K_{c}^{K-C}\right.$, Table 11). The results are depicted on Figure 20. For the PI paste the measured permeability was of the same order as the one obtained using eq. (18) but was three times higher. This suggested that the effect of porosity clogging was counterbalanced by microcracking. The results were however very different for the blended cements, the discrepancy between experimental and computed data increased with the cracking index $\left(I_{C}\right)$. This suggested that in that specific case microcracking was the main cause of permeability increase and that clogging had negligible impact. 


\begin{tabular}{ccccc}
\hline Permeability $\left(\times 10^{-22} \mathrm{~m}^{2}\right)$ & $\mathrm{PI}$ & PIII & PV & PBP \\
\hline$K_{n c}$ & 2.70 & 0.26 & 0.50 & 0.45 \\
$K_{c}^{\text {exp }}$ & 1.16 & 74.82 & 74.39 & 81.48 \\
$K_{c}^{K-C}($ eq. 18$)$ & 0.35 & 0.08 & 0.16 & 0.24 \\
\hline
\end{tabular}

487

488

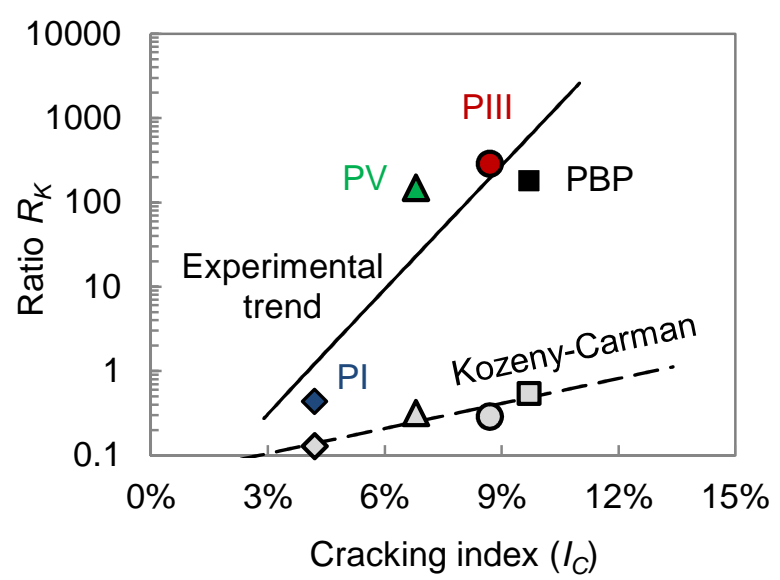

Figure 20: Competition between porosity clogging and cracking.

\section{Conclusion}

The impact of carbonation on unsaturated water transport was addressed using four pastes made with different binders (three commercial cements and a low-pH blend). In the framework of a simplified approach for the description of unsaturated water transport, three physical parameters were characterised: porosity, water desorption isotherm and permeability. The samples were carbonated at a $\mathrm{CO}_{2}$ content of $3 \%$ to ensure representativeness and mitigate cracking (as already observed at $50 \%$ ). The precipitation of calcium carbonate led to porosity reduction, the extent of which was related to the initial composition of the paste (portlandite and C-S-H contents). The water desorption curves were significantly altered by carbonation:

- a drop of water content was observed over all the $\mathrm{RH}$ range according to porosity clogging;

- the isotherms morphology was changed in relation to pore size distribution modification.

The cup-method test was a good alternative to inverse analysis for the assessment of the unsaturated permeability. The results highlighted a competition between two concomitant phenomena: porosity clogging and microcracking. A decrease of permeability after carbonation was observed for Portland 
cement (CEM I): porosity clogging prevailed over microcracking. On the contrary and despite the fall of porosity, significant permeability increase was obtained for the blended cements: microcracking prevailed over clogging. Permeability was found to increase with cracking (digital image processing) and more specifically with the initial C-S-H content. C-S-H decalcification revealed by ${ }^{29} \mathrm{Si}$ NMR was believed to be the main cause of shrinkage resulting in cracking.

This study was only a first step; these tests should also be conducted using concretes. The presence of aggregates might help mitigating the consequences of carbonation shrinkage and change the cracking pattern (the cracks could be concentrated around the aggregates).

\section{Acknowledgments.}

The authors would like to thank Andra for financial support. Lafarge, Calcia, Holcim kindly accepted to supply cements free of charge.

\section{References}

[1] K. Tuutti, Corrosion of steel in concrete, Swedish Cement and Concrete Research Institute, 1982, pp. 468.

[2] S.E. Pihlajavaara, Some results of the effect of carbonation on the porosity and pore size distribution of cement paste, Materials and Structures, 1 (1968) 521-526.

[3] V.G. Papadakis, C.G. Vayenas, M.G. Fardis, Fundamental modeling and experimental investigation of concrete carbonation, ACI Materials Journal, 88 (1991) 363-373.

[4] Y.F. Houst, F.H. Wittmann, Influence of porosity and water content on the diffusivity of $\mathrm{CO}_{2}$ and $\mathrm{O}_{2}$ through hydrated cement paste, Cement and Concrete Research, 24 (1994) 1165-1176.

[5] V.T. Ngala, C.L. Page, Effects of carbonation on pore structure and diffusional properties of hydrated cement pastes, Cement and Concrete Research, 27 (1997) 995-1007.

[6] P.A. Claisse, H. El-Sayad, I.G. Shaaban, Permeability and pore volume of carbonated concrete, ACI Materials Journal, 96 (1999) 378-382.

[7] M. Thiery, V. Baroghel-Bouny, A. Morandeau, P. Dangla, Impact of carbonation on the microstructure and transfer properties of cement-based materials, Symposium TransfertLille, France, 2012.

[8] A. Morandeau, M. Thiéry, P. Dangla, Investigation of the carbonation mechanism of $\mathrm{CH}$ and C-S-H in terms of kinetics, microstructure changes and moisture properties, Cement and Concrete Research, 56 (2014) 153-170.

[9] P.J. Dewaele, E.J. Reardon, R. Dayal, Permeability and porosity changes associated with cement grout carbonation, Cement and Concrete Research, 21 (1991) 441-454.

[10] B. Johannesson, P. Utgennant, Microstructural changes caused by carbonation of cement mortar, Cement and Concrete Research, 31 (2001) 925-931. 
[11] G.G. Litvan, A. Meyer, Carbonation of granulated blast furnace slag cement concrete during twenty years of field exposure, ACI Special Publication, 91 (1986) 1445-1462.

540 [12] A. Morandeau, M. Thiéry, P. Dangla, Impact of accelerated carbonation on OPC cement paste 541 blended with fly ash, Cement and Concrete Research, 67 (2015) 226-236.

[13] A. Morandeau, Carbonatation atmosphérique des systèmes cimentaires à faible teneur en portlandite (in French), Ph.D. Thesis, Paris-Est University, 2013.

[14] Y.F. Houst, Carbonatation et retrait de la pâte de ciment durcie (in French), Ph.D. Thesis, Ecole Polytechnique Fédérale de Lausanne, 1992.

[15] L.J. Parrott, Variations of water absorption rate and porosity with depth from an exposed concrete surface: Effects of exposure conditions and cement type, Cement and Concrete Research, 22 (1992)

\section{1077-1088.}

[16] N. Hyvert, Application de l'approche probabiliste à la durabilité des produits préfabriqués en béton (in French), , Ph.D. Thesis, Toulouse University, 2009.

[17] G.R. Martin, A method for determining the relative permeability of concrete using gas, Magazine of Concrete Research, 38 (1986) 90-94.

[18] R.K. Dhir, P.C. Hewlett, E.A. Bryars, I.G. Shaaban, A new technique for measuring the air permeability of near-surface concrete, Magazine of Concrete Research, 47 (1995) 167-176.

[19] H.-W. Song, S.-J. Kwon, Permeability characteristics of carbonated concrete considering capillary pore structure, Cement and Concrete Research, 37 (2007) 909-915.

[20] P.H.R. Borges, J.O. Costa, N.B. Milestone, C.J. Lynsdale, R.E. Streatfield, Carbonation of CH and C-S-H in composite cement pastes containing high amounts of BFS, Cement and Concrete Research, 40 (2010) 284-292.

[21] X. Wang, M. Thiéry, V. Baroghel-Bouny, Influence of carbonation and chemical activity of water on coupled moisture-ions transport in cementitious materials, Defect and Diffusion Forum, 323-325 (2012) 263-268.

[22] J. Selih, A.C.M. Sousa, T.W. Bremner, Moisture transport in initially fully saturated concrete during drying, Transport in Porous Media, 24 (1996) 81-106.

[23] D. Gawin, B.A. Schrefler, Thermo-hydro-mechanical analysis of partially saturated porous materials, Engineering Computations, 13 (1996) 113-143.

[24] O. Coussy, Poromechanics, John Wiley \& Sons Ltd2004.

568

[25] F. Meftah, S. Dal Pont, Staggered finite volume modeling of transport phenomena in porous materials with convective boundary conditions, Transport in Porous Media, 82 (2010) 275-298.

[26] M. Mainguy, O. Coussy, V. Baroghel-Bouny, Role of air pressure in drying of weakly permeable materials, Journal of Engineering Mechanics (ASCE), 127 (2001) 582-592.

[27] M. Thiery, V. Baroghel-Bouny, N. Bourneton, G. Villain, C. Stéfani, Modélisation du séchage des bétons, analyse des différents modes de transfert hydrique (in French), European Journal of Environmental and Civil Engineering, 11 (2007) 541-577.

[28] M. Thiery, P. Belin, V. Baroghel-Bouny, M.D. Nguyen, Modeling of isothermal drying process in cementitious materials, analysis of the moisture transfer and proposal of simplified approaches, in: J.F. Shao, N. Burlion (Eds.) $3^{\text {rd }}$ international conference GeoProc, Wiley, Lille (France), 2008, pp. 571579.

[29] L.A. Richards, Capillary conduction of liquids through porous mediums, Physics, 1 (1931) 318333.

[30] V. Baroghel-Bouny, Water vapour sorption experiments on hardened cementitious materials: Part I. Essential tool for analysis of hygral behaviour and its relation to pore structure, Cement and Concrete Research, 37 (2007) 414-437.

[31] C. Cau Dit Coumes, S. Courtois, D. Nectoux, S. Leclercq, X. Bourbon, Formulating a lowalkalinity, high-resistance and low-heat concrete for radioactive waste repositories, Cement and Concrete Research, 36 (2006) 2152-2163. 
[32] M. Codina, C. Cau-dit-Coumes, P. Le Bescop, J. Verdier, J.P. Ollivier, Design and characterization of low-heat and low-alkalinity cements, Cement and Concrete Research, 38 (2008) 437-448.

590

[33] E. Drouet, Impact de la température sur la carbonatation des matériaux cimentaires : prise en compte des transferts hydriques (in French), Ph.D. Thesis, Ecole Normale Supérieure de Cachan, 2010, pp. 315.

[34] E. Drouet, S. Poyet, J.M. Torrenti, Temperature influence on water transport properties in hardened cement pastes, Cement and Concrete Research, (under review) (2015).

[35] R. Barneyback, S. Diamond, Expression and analysis of pore fluid from hardened pastes and mortars, Cement and Concrete Research, 11 (1981) 279-285.

[36] M. Cyr, A. Daidié, Optimization of a high-pressure pore water extraction device, Review of Scientific Instruments, 78 (2007) 023906.

[37] P.C. Kreijger, The skin of concrete, composition and properties, Materials and Structures, 17 (1990) 275-283.

[38] J. Khatib, P.S. Mangat, Porosity of cement paste cured at $45^{\circ} \mathrm{C}$ as a function of location relative to casting position, Cement and Concrete Research, 25 (2003) 97-108.

[39] E.E. Demirci, R. Şahin, Comparison of carbonation resistance and uniformity of SCC and CC core samples, Magazine of Concrete Research, 2014, pp. 531-539.

[40] C. Carde, R. François, J.-M. Torrenti, Leaching of both calcium hydroxide and C-S-H from cement paste: Modeling the mechanical behavior, Cement and Concrete Research, 26 (1996) 1257-1268.

[41] S. Poyet, P. Le Bescop, M. Pierre, L. Chomat, C. Blanc, Accelerated leaching of cementitious materials using ammonium nitrate $(6 \mathrm{M})$ : influence of test conditions, European Journal of Environmental and Civil Engineering, 16 (2012) 336-351.

[42] G. Verbeck, Carbonation of Hydrated Portland Cement, ASTM Special Publication, 205 (1958) 1736.

[43] M. Vénuat, Relation entre la carbonatation du béton et les phénomènes de corrosion des armatures du béton (in French), Annales de l'ITBTP, 364 (1978) 42-47.

[44] I. Galan, C. Andrade, M. Castellote, Natural and accelerated $\mathrm{CO}_{2}$ binding kinetics in cement paste at different relative humidities, Cement and Concrete Research, 49 (2013) 21-28.

[45] M. Castellote, L. Fernandez, C. Andrade, C. Alonso, Chemical changes and phase analysis of OPC pastes carbonated at different $\mathrm{CO}_{2}$ concentrations, Materials and Structures, 42 (2009) 515-525.

[46] G. Villain, G. Platret, Two experimental methods to determine carbonation profiles in concrete, ACI Materials Journal, 29 (2006) 265-271.

[47] R.A. Olson, H.M. Jennings, Estimation of C-S-H content in a blended cement paste using water adsorption, Cement and Concrete Research, 31 (2001) 351-356.

[48] I.G. Richardson, A.R. Brough, R. Brydson, G.W. Groves, C.M. Dobson, Location of Aluminum in Substituted Calcium Silicate Hydrate (C-S-H) Gels as Determined by ${ }^{29} \mathrm{Si}$ and ${ }^{27} \mathrm{Al}$ NMR and EELS, Journal of the American Ceramic Society, 76 (1993) 2285-2288.

[49] P. Faucon, A. Delagrave, J.C. Petit, C. Richet, J.M. Marchand, H. Zanni, Aluminum incorporation in Calcium Silicate Hydrates (C-S-H) depending on their Ca/Si ratio, Journal of Physical Chemistry B, 103 (1999) 7796-7802.

[50] F. Brunet, P. Bertani, T. Charpentier, A. Nonat, J. Virlet, Application of ${ }^{29}$ Si Homonuclear and ${ }_{1}^{1}{ }_{-}{ }^{29}$ Si Heteronuclear NMR Correlation to Structural Studies of Calcium Silicate Hydrates, The Journal of Physical Chemistry B, 108 (2004) 15494-15502.

[51] J. Skibsted, C. Hall, Characterization of cement minerals, cements and their reaction products at the atomic and nano scale, Cement and Concrete Research, 38 (2008) 205-225.

[52] T.F. Sevelsted, D. Herfort, J. Skibsted, ${ }^{13} \mathrm{C}$ chemical shift anisotropies for carbonate ions in cement minerals and the use of ${ }^{13} \mathrm{C},{ }^{27} \mathrm{Al}$ and ${ }^{29} \mathrm{Si} \mathrm{MAS} \mathrm{NMR}$ in studies of Portland cement including limestone additions, Cement and Concrete Research, 52 (2013) 100-111. 
[53] F. Brunet, T. Charpentier, C.N. Chao, H. Peycelon, A. Nonat, Characterization by solid-state NMR and selective dissolution techniques of anhydrous and hydrated CEM V cement pastes, Cement and Concrete Research, 40 (2010) 208-219.

[54] AFNOR, Essai pour béton durci - essai de porosité et de masse volumique (in French), French Standard NF P18-459, (2010).

[55] L. Wadsö, K. Svennberg, A. Dueck, An experimentally simple method for measuring sorption isotherms, Drying Technology, 22 (2004) 2427-2440.

[56] D.S. Carr, B.L. Harris, Solutions for maintaining constant relative humidity, Industrial and Engineering Chemistry, 41 (1949) 2014-2015.

[57] A. Wexler, S. Hasegawa, Relative humidity-temperature relationships of some saturated salt solutions in temperature range $0^{\circ} \mathrm{C}$ to $50^{\circ} \mathrm{C}$, Journal of Research of the National Bureau of Standards, 53 (1954) 19-26.

[58] J.F. Young, Humidity control in the laboratory using salt solutions - a review, Journal of Applied Chemistry, 17 (1967) 241-245.

[59] L. Greenspan, Humidity fixed points of binary saturated aqueous solutions, Journal of Research of the National Bureau of Standards - A, Physics and Chemistry, 81A (1977) 89-96.

[60] S. Poyet, Experimental investigation of the effect of temperature on the first desorption isotherm of concrete, Cement and Concrete Research, 39 (2009) 1052-1059.

[61] Z. Pavlík, J. Žumár, I. Medved, R. Černý, Water Vapor Adsorption in Porous Building Materials: Experimental Measurement and Theoretical Analysis, Transport in Porous Media, 91 (2012) 939-954.

[62] S. Brunauer, P.H. Emmett, E. Teller, Adsorption of gases in multimolecular layers, Journal of the American Chemical Society, 60 (1938) 309-319.

[63] K.S.W. Sing, E. D.S., R.A.W. Haul, L. Moscou, R.A. Pierotti, J. Rouquérol, T. Siemieniewska, Reporting physisorption data for gas/solid systems with special reference to the determination of surface area and porosity (Recommendations 1984), Pure and Applied Chemistry, 57 (1985) 603-619.

[64] J.B. Condon, Surface area and porosity determinations by physisorption - Measurements \& theory, Elsevier2006.

[65] P.H. Emmett, S. Brunauer, The Use of Low Temperature van der Waals Adsorption Isotherms in Determining the Surface Area of Iron Synthetic Ammonia Catalysts, Journal of the American Chemical Society, 59 (1937) 1553-1564.

[66] S.J. Gregg, K.S.W. Sing, Adsorption, surface area and porosity, 2nd ed ed., Academic Press, London, United Kingdom, 1982.

[67] V. Baroghel-Bouny, M. Mainguy, T. Lassabatere, O. Coussy, Characterization and identification of equilibrium and transfer moisture properties for ordinary and high-performance cementitious materials, Cement and Concrete Research, 29 (1999) 1225-1238.

[68] Y. Mualem, A new model for predicting the hydraulic conductivity of unsaturated porous media, Water Resources Research, 12 (1976) 513-522.

[69] M.T. van Genuchten, A closed-form equation for predicting the hydraulic conductivity of unsaturated soils, Soil Science Society of America Journal, 44 (1980) 892-898.

[70] P.A.M. Basheer, Permeation analysis, in: V.S. Ramachandran, J.J. Beaudouin (Eds.) Handbook of analytical techniques in concrete science and technlogy, Noyes Publications, Park Ridge, New Jersey, U.S.A., 2001, pp. 658-737.

[71] E.G. Swenson, P.J. Sereda, Mechanism of the carbonation shrinkage of lime and hydrated cement, Journal of Applied Chemistry, 18 (1968) 111-117.

[72] G.W. Groves, D.I. Rodway, I.G. Richardson, The carbonation of hardened pastes, Advances in Cement Research, 3 (1990) 117-125.

[73] J.R. Johnstone, F.P. Glasser, Carbonation of single crystals of portlandite in cement paste, Proceedings of the 9th International Conference on the Chemistry of CementNew Dehly, India, 1992, pp. 370-377. 
[74] P. Sun, J.R. Grace, C.J. Lim, C.J. Anthony, A discrete pore-size-distribution-based gas-solid model and its application to the reaction, Chemical Engineering Science, 63 (2008) 57-70.

[75] C. Leech, D. Lockington, R.D. Hooton, G. Galloway, G. Cowin, P. Dux, Validation of Mualem's conductivity model and prediction of saturated permeability from sorptivity, ACI Materials Journal, 105 (2008) 44-51.

[76] S. Poyet, S. Charles, N. Honoré, V. L'Hostis, Assessment of the unsaturated water transport properties of an old concrete: determination of the pore-interaction factor, Cement and Concrete 692 Research, 41 (2011) 1015-1023.

693 [77] J.H.M. Wösten, M.T. van Genuchten, Using texture and other soil properties to predict the unsaturated soil hydraulic functions, Soil Science Society of America Journal, 52 (1988) 1762-1770.

695

[78] W.M. Schuh, R.L. Cline, Effect of soil properties on unsaturated hydraulic conductivity poreinteraction factors, Soil Science Society of America Journal, 54 (1990) 1509-1519.

[79] K. Kosugi, General model for unsaturated hydraulic conductivity for soils with lognormal pore-size distribution, Soil Science Society of America Journal, 63 (1999) 270-277.

[80] J.J. Chen, J.J. Thomas, H.M. Jennings, Decalcification shrinkage of cement paste, Cement and Concrete Research, 36 (2006) 801-809.

[81] T.C. Powers, A hypothesis on carbonation shrinkage, Journal of the PCA Research \& Development Laboratories, 4 (1962) 40-50.

[82] K. Kamimura, P.J. Sereda, E.G. Swenson, Changes in weight and dimensions in the drying and carbonation of Portland cement mortars, Magazine of Concrete Research, 17 (1965) 5-14.

[83] Y.F. Houst, Carbonation shrinkage of hydrated cement paste, $4^{\text {th }} \mathrm{CANMET/ACI}$ International Conference on Durability of ConcreteOttawa, Canada, 1997, pp. 481-491.

[84] J. Han, W. Sun, G. Pan, W. Caihui, Monitoring the evolution of accelerated carbonation of hardened cement pastes by X-Ray computed tomography, ASCE Journal of Materials in Civil Engineering, 25 (2013) 347-354.

[85] K. Wan, Q. Xu, Y. Wang, G. Pan, 3D spatial distribution of the calcium carbonate caused by carbonation of cement paste, Cement and Concrete Research, 45 (2014) 255-263.

[86] P.C. Carman, Fluid flow through granular beds, Transactions of the Institution of Chemical Engineers, 15 (1937) S32-S48.

[87] B. Bary, A. Sellier, Coupled moisture-carbon dioxide-calcium transfer model for carbonation of concrete, Cement and Concrete Research, 34 (2004) 1859-1872.

[88] W.D. Carrier, Goodbye, Hazen; Hello, Kozeny-Carman, ASCE Journal of Geotechnical and Environmental Engineering, 129 (2003) 1054-1056.

[89] M. Xie, K.U. Mayer, F. Claret, P. Alt-Epping, D. Jacques, C. Steefel, C. Chiaberge, J. Simunek, Implementation and evaluation of permeability-porosity and tortuosity-porosity relationships linked to mineral dissolution-precipitation, Comput Geosci, (to be published in 2015). 